\title{
Gamma radiation-induced oxidation, doping, and etching of two-dimensional MoS2crystals
}

DOI:

10.1021/acs.jpcc.0c10095

\section{Document Version}

Final published version

Link to publication record in Manchester Research Explorer

\section{Citation for published version (APA):}

Isherwood, L. H., Athwal, G., Spencer, B. F., Casiraghi, C., \& Baidak, A. (2021). Gamma radiation-induced oxidation, doping, and etching of two-dimensional MoS 2 crystals. Journal of Physical Chemistry C, 125(7), 42114222. https://doi.org/10.1021/acs.jpcc.0c10095

\section{Published in:}

Journal of Physical Chemistry C

\section{Citing this paper}

Please note that where the full-text provided on Manchester Research Explorer is the Author Accepted Manuscript or Proof version this may differ from the final Published version. If citing, it is advised that you check and use the publisher's definitive version.

\section{General rights}

Copyright and moral rights for the publications made accessible in the Research Explorer are retained by the authors and/or other copyright owners and it is a condition of accessing publications that users recognise and abide by the legal requirements associated with these rights.

\section{Takedown policy}

If you believe that this document breaches copyright please refer to the University of Manchester's Takedown Procedures [http://man.ac.uk/04Y6Bo] or contact uml.scholarlycommunications@manchester.ac.uk providing relevant details, so we can investigate your claim.

\section{OPEN ACCESS}




\title{
Gamma Radiation-Induced Oxidation, Doping, and Etching of Two- Dimensional $\mathrm{MoS}_{2}$ Crystals
}

\author{
Liam H. Isherwood, Gursharanpreet Athwal, Ben F. Spencer, Cinzia Casiraghi, and Aliaksandr Baidak*
}

Cite This: J. Phys. Chem. C 2021, 125, 4211-4222

Read Online

ABSTRACT: Two-dimensional (2D) $\mathrm{MoS}_{2}$ is a promising material for future electronic and optoelectronic applications. $2 \mathrm{D} \mathrm{MoS}$ devices have been shown to perform reliably under irradiation conditions relevant for a low Earth orbit. However, a systematic investigation of the stability of $2 \mathrm{D}$ $\mathrm{MoS}_{2}$ crystals under high-dose gamma irradiation is still missing. In this work, absorbed doses of up to $1000 \mathrm{kGy}$ are administered to $2 \mathrm{D} \mathrm{MoS}_{2}$. Radiation damage is monitored via optical microscopy and Raman, photoluminescence, and X-ray photoelectron spectroscopy techniques. After irradiation with $500 \mathrm{kGy}$ dose, p-doping of the monolayer $\mathrm{MoS}_{2}$ is observed and attributed to the adsorption of $\mathrm{O}_{2}$ onto created vacancies. Extensive oxidation of the $\mathrm{MoS}_{2}$ crystal is attributed to reactions involving the products of adsorbate radiolysis. Edge-selective radiolytic etching of the uppermost layer in $2 \mathrm{D} \mathrm{MoS}_{2}$ is attributed to the high reactivity of active edge sites. After irradiation with $1000 \mathrm{kGy}$, the monolayer $\mathrm{MoS}_{2}$ crystals appear to be completely etched. This holistic study reveals the previously unreported effects of high-dose gamma irradiation on the physical and chemical properties of $2 \mathrm{D} \mathrm{MoS}$. Consequently, it demonstrates that radiation shielding, adsorbate concentrations, and required device lifetimes must be carefully considered, if devices incorporating $2 \mathrm{D} \mathrm{MoS}_{2}$ are intended for use in high-dose radiation environments.

\section{INTRODUCTION}

Nuclear and space applications are the primary fields that could experience a technological step change due to the implementation of light-weight materials and devices with enhanced capabilities, offered by two-dimensional (2D) materials such as transition metal dichalcogenides (TMDCs). However, the successful deployment of 2D TMDCs in such applications can only be achieved if these materials are resilient and durable upon exposure to high doses of ionizing radiation. ${ }^{1}$ Our work addresses this important question by investigating the gamma-radiation-induced processes in $\mathrm{MoS}_{2}$ crystals within the high-dose regime under ambient conditions.

2D TMDCs are a class of layered van der Waals solids with the general formula $\mathrm{MX}_{2}$ that exhibit a plethora of magnetic, electronic, and optical properties. ${ }^{2,3}$ Group VI TMDCs, where $\mathrm{M}=\mathrm{Mo}$ or $\mathrm{W}$ and $\mathrm{X}=\mathrm{S}$ or $\mathrm{Se}$, are semiconductors whose band gaps progressively increase as the crystal thickness is reduced; an indirect-direct transition is observed in monolayer $(1 \mathrm{~L})$ crystals. $^{4,5}$ In particular, $1 \mathrm{~L} \mathrm{MoS}_{2}$ possesses a $1.9 \mathrm{eV}$ direct band gap, ${ }^{6}$ which makes it a promising candidate for photovoltaic applications. ${ }^{7-9}$ With regard to electronic applications, field-effect transistors incorporating 2D $\mathrm{MoS}_{2}$ exhibit subthreshold swing values close to the limit of $\sim 60 \mathrm{mV} \mathrm{dec}{ }^{-1}$ at room temperature, ${ }^{10}$ while $2 \mathrm{D} \mathrm{MoS}_{2}$ nanocomposites have proven to be effective electrode materials in Li-ion batteries. ${ }^{11}$ The aforementioned applications are all desirable components of satellite electronics. Moreover, the atomically thin nature and high electron mobility ${ }^{10}$ of $2 \mathrm{D}$ $\mathrm{MoS}_{2}$ suggest that low-weight devices with minimal power consumption can be fabricated, both of which are prerequisites for satellite instrumentation.

However, in order for a material to be incorporated into applications intended for use in radiation environments, such as the space or nuclear industries, a comprehensive understanding of its radiation damage mechanisms is mandatory. This necessity stems from the adverse effects that the specific radiation field can have on the physical and chemical properties of the material, resulting in the degradation of the device performance. For instance, when a material is irradiated with ions or electrons, atoms can be displaced from their lattice sites due to elastic collisions involving the incident projectiles. Displacement damage must still be considered in the case of gamma irradiation on account of the energetic recoil electrons produced during the Compton scattering of gamma rays. As a result, the vacancies produced by the displacement damage can introduce defect states within the band gap of photoactive materials. These defect states deteriorate the performance of the solar cell by promoting carrier generation, recombination, trapping, and compensation mechanisms. ${ }^{12}$ In addition to displacement damage caused by energetic recoil electrons, the holes produced during the Compton scattering can form

Received: November 9, 2020

Revised: January 4, 2021

Published: February 10, 2021 
oxides and interface charge traps in field-effect transistors. Hence, this ionization damage creates unintended charge concentrations and parasitic fields altering the device performance. $^{13}$

The effect of ion and electron irradiation on the structural, $^{14-17}$ electronic $^{18-22}$ and optical ${ }^{23-26}$ properties of $2 \mathrm{D} \mathrm{MoS}_{2}$ has been extensively researched. ${ }^{27}$ Only a few studies have evaluated the effect of gamma irradiation on the physical properties of 2D group VI TMDCs. Using a ${ }^{60} \mathrm{Co}$ source, Felix et al. irradiated $1 \mathrm{~L} \mathrm{WS}_{2}$ crystals with an absorbed dose of 400 Gy and observed ferromagnetic hysteresis, which they attributed to a defect configuration involving one $\mathrm{W}$ and two $S$ vacancies. ${ }^{28}$ Vogl et al. exposed various $1 \mathrm{~L}$ group VI TMDC crystals, produced by micromechanical exfoliation (MME), ${ }^{29}$ to gamma radiation using a ${ }^{22} \mathrm{Na}$ source. ${ }^{30}$ Although the photoluminescence (PL) spectrum of $\mathrm{MoS}_{2}, \mathrm{MoSe}_{2}$, and $\mathrm{WSe}_{2}$ changed negligibly with increasing dose, a significant linear increase in the PL intensity was observed for $\mathrm{WS}_{2}$ crystals as a function of radiation exposure. This was attributed to the passivation of $S$ vacancies by the dissociation of atmospheric $\mathrm{O}_{2}$ and its inclusion into the crystal lattice to form $\mathrm{WS}_{2-x} \mathrm{O}_{x}$ species. Moreover, they fabricated field-effect transistors incorporating 2D MoS 2 that showed negligible changes in current-voltage characteristics after irradiation with an absorbed dose equivalent to 2170 years at $500 \mathrm{~km}$ above the polar caps. Thus, Vogl et al. demonstrated that 2D TMDC devices can successfully withstand the radiation environment of the low Earth orbit.

However, the mean dose rates in the low Earth orbit are typically $<20.8 \mu \mathrm{Gy} \mathrm{h}^{-1,31}$ which are significantly lower than the $\sim 200 \mathrm{~Gy} \mathrm{~h}^{-1}$ dose rate at the vessel walls of a reactor. ${ }^{32}$ Furthermore, the reprocessing of the spent nuclear fuel and the storage of high-level radioactive waste might see comparably high dose rates. First-principles calculations by Zhang et al. demonstrate that $2 \mathrm{D} \quad \mathrm{MoS}_{2}$ could be used to sequester problematic $\mathrm{Cs}, \mathrm{Sr}$, and $\mathrm{Ba}$ radionuclides commonly found in nuclear waste. ${ }^{33}$ In addition to testing the adsorption capacity of $\mathrm{MoS}_{2}$, the required experimental studies ought to include an investigation into the radiolytic effects induced by the radioactive decay of the adsorbed nuclides on the surface of $\mathrm{MoS}_{2}$ in the presence of water.

Considering an even broader range of applications, a good understanding of the free-radical processes at the $\mathrm{MoS}_{2}$-water interface also provides insights into the proposed uses of $\mathrm{MoS}_{2}$ as a radioprotector ${ }^{34}$ or, conversely, as a radiosensitizer ${ }^{35}$ for the future clinical treatment of cancer. In addition, ion irradiation has been proven to be an excellent tool to modify $2 \mathrm{D}$ materials, ${ }^{36}$ but the full potential of the gamma irradiation technique for controlled defect engineering in TMDCs is yet to be explored.

To the best of our knowledge, just a handful of studies have addressed the effects of the high-dose gamma irradiation of $2 \mathrm{D}$ $\mathrm{MoS}_{2}$. For example, Ozden et al. utilized a ${ }^{60} \mathrm{Co}$ source to irradiate few-layer 2D $\mathrm{MoS}_{2}$ films, produced by chemical vapor deposition (CVD), ${ }^{37}$ with an absorbed dose of $1200 \mathrm{kGy}$ under ambient conditions. ${ }^{38}$ They observed the disappearance of the out-of-plane $A_{1 g}$ and in-plane $E_{2 g}^{1}$ normal vibrational modes and the formation of $\mathrm{MoO}_{x}$ species after irradiation, suggesting a significant increase in the chemical and structural disorder. Similarly, $\mathrm{He}$ et al. also utilized a ${ }^{60} \mathrm{Co}$ source to irradiate $\mathrm{MoS}_{2}$, synthesized via a hydrothermal method, with absorbed doses between $1 \mathrm{kGy}$ and $1000 \mathrm{kGy} .{ }^{39}$ Conversely, they observed (1) no $\mathrm{MoO}_{x}$ formation, (2) an improvement in crystallinity, and (3) red-shifted $A_{1 g}$ and $E_{2 g}^{1}$ modes with significant intensities after irradiation.

It is evident that a comprehensive, noncontradictory understanding of the effects of the high-dose gamma irradiation on the morphology, vibrational properties, and chemical composition of $2 \mathrm{D} \mathrm{MoS}$ is still missing. To address these open questions, we utilized a ${ }^{60} \mathrm{Co}$ source to irradiate $2 \mathrm{D}$ and bulk $\mathrm{MoS}_{2}$ crystals with absorbed doses between 40 and $1000 \mathrm{kGy}$. Our results show that both $\mathrm{S}$ atoms and $\mathrm{Mo}^{\mathrm{IV}}$ centers at the surface of the $\mathrm{MoS}_{2}$ crystals are oxidized upon gamma irradiation under ambient conditions to yield $\mathrm{Mo}^{\mathrm{VI}} \mathrm{S}_{y} \mathrm{O}_{x}$ and sulfate species via a series of intermediates. Regarding the morphology of irradiated $\mathrm{MoS}_{2}$, edge-selective radiolytic etching of the uppermost $\mathrm{MoS}_{2}$ layers in $2 \mathrm{D}$ crystals is observed after irradiation with an absorbed dose of $500 \mathrm{kGy}$. Concerning radiation-induced changes in the vibrational and optical properties, a blue shift and line width decrease of the $A_{1}^{\prime}$ mode in $1 \mathrm{~L} \mathrm{MoS}_{2}$ is correlated with a blue shift of the PL signal and attributed to $\mathrm{p}$-doping caused by $\mathrm{O}_{2}$ adsorption onto vacancies. The observed changes are attributed to the defect production caused by both displacement damage and reactions involving the radiolysis products of adsorbed water and adventitious carbon. Importantly, significant oxidation, etching, and doping of $2 \mathrm{D} \mathrm{MoS}_{2}$ are observed after an absorbed dose of $500 \mathrm{kGy}$ is administered. This absorbed dose corresponds to $\sim 104$ days at the vessel walls of a reactor; ${ }^{32}$ hence, appropriate consideration must be given to shielding, adsorbate concentrations, and required device lifetimes, if $2 \mathrm{D}$ $\mathrm{MoS}_{2}$ is intended for use in high-dose radiation environments such as the nuclear industry.

\section{METHODS}

2.1. Micromechanical Exfoliation. Mono-, bi-, tri-, and quadri-layer and bulk $\mathrm{MoS}_{2}$ samples were prepared via the mechanical cleavage of molybdenite crystals (Manchester Nanomaterials) using dicing tape. The exfoliated flakes were deposited onto $\mathrm{SiO}_{2} / \mathrm{Si}$ substrates (IDB Technologies, oxide thickness ca. $300 \mathrm{~nm}$ ), which had been sonicated in acetone (10 $\mathrm{min})$ and propan-2-ol ( $5 \mathrm{~min}$ ) before being dried under a nitrogen flow. Prior to deposition, the substrates were heated to $130{ }^{\circ} \mathrm{C}$ under ambient conditions to suppress the formation of an interfacial water layer. Optical microscopy was used to identify monolayer and few-layer flakes on account of their distinctive optical contrast. The thicknesses of the $\mathrm{MoS}_{2}$ flakes were then confirmed via Raman spectroscopy.

2.2. Chemical Vapor Deposition. A $1 \mathrm{~cm} \times 1 \mathrm{~cm}$ polycrystalline film of the monolayer $\mathrm{MoS}_{2}$ on $\mathrm{SiO}_{2} / \mathrm{Si}$ (2DLayer, Atomix Inc., Durham, NC) was cut into four 5 $\mathrm{mm} \times 5 \mathrm{~mm}$ sections using a glass scribe. Prior to irradiation, each sample was characterized via Raman and photoluminescence spectroscopy techniques.

2.3. Gamma Irradiation. Gamma irradiations were performed using a self-contained Foss Therapy Service Inc. $812{ }^{60} \mathrm{Co}$ source located at the Dalton Cumbrian Facility, University of Manchester. The dose rates administered to the samples varied between 265 and $365 \mathrm{~Gy} / \mathrm{min}$, determined using the ionization chamber detector. Prior to irradiation, the $\mathrm{MoS}_{2}$ samples were transferred into crimp-sealed borosilicate vials $(10 \mathrm{~mL}$ capacity) under ambient conditions. The absorbed doses administered to the $\mathrm{MoS}_{2}$ samples prepared via micromechanical exfoliation and chemical vapor deposition varied from $40 \mathrm{kGy}$ up to $1000 \mathrm{kGy}$. The sample used to investigate the influence of adsorbed water on the radiation 


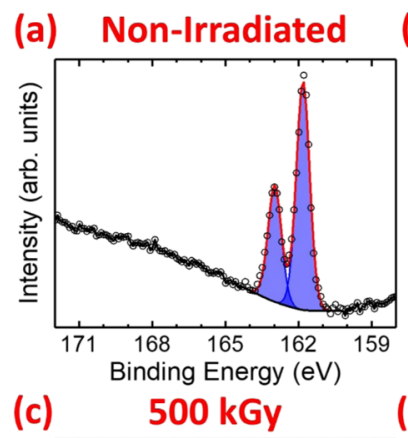

(b) $100 \mathrm{kGy}$
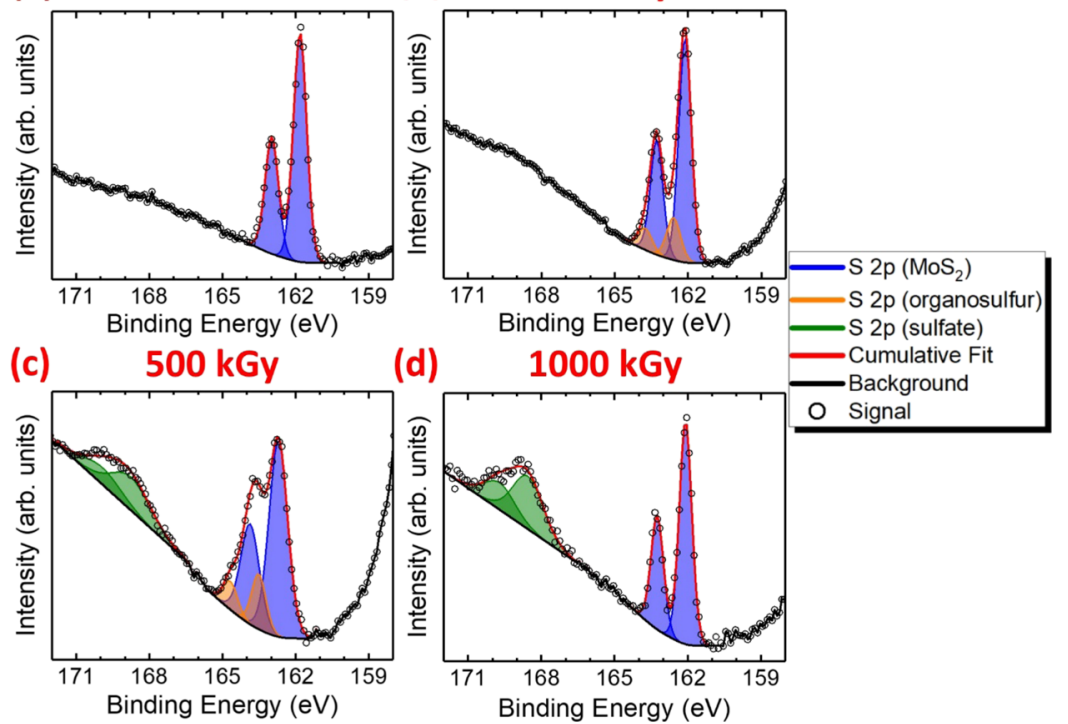

Figure 1. Deconvoluted S 2p X-ray photoelectron spectra of $\mathrm{MoS}_{2}$ crystals, deposited by micromechanical exfoliation: (a) prior to irradiation and after irradiation with the absorbed doses of (b) $100 \mathrm{kGy}$, (c) $500 \mathrm{kGy}$, and (d) $1000 \mathrm{kGy}$.

damage mechanisms in $\mathrm{MoS}_{2}$ was placed inside a constant humidity chamber that contained a beaker with pure water. This environment possessed a relative humidity of about $95 \%$. The sample was conditioned for 5 days inside the chamber prior to irradiation. The irradiation took place immediately after the sample was taken from the constant humidity chamber.

2.4. Raman Spectroscopy. Raman measurements were acquired in backscattering geometry under ambient conditions using a WITec Alpha300 spectrometer equipped with 1800 lines $\mathrm{mm}^{-1}$ grating and a $100 \times$ objective lens (numerical aperture $=0.95$ ), resulting in a spectral resolution of $\sim 1 \mathrm{~cm}^{-1}$ and a spatial resolution of $\sim 330 \mathrm{~nm}$. An excitation wavelength of $514.5 \mathrm{~nm}$ was used for all measurements, and laser power was kept below $0.15 \mathrm{~mW}$ to avoid thermal damage or local heating effects. WITec Project 2.08 was used to fit all Raman signals using Lorentzian line shapes and to create Raman maps.

2.5. Photoluminescence Spectroscopy. PL measurements were also acquired under ambient conditions using a WITec Alpha300 spectrometer equipped with a $514.5 \mathrm{~nm}$ laser, operated below $0.15 \mathrm{~mW}$, and a $100 \times$ objective lens. However, 600 lines $\mathrm{mm}^{-1}$ grating was used to increase the spectral window, enabling the measurement of both the $\mathrm{A}^{-}$ trion and the $\mathrm{B}$ exciton at higher energies. Data processing is analogous to that described for Raman measurements with the exception that Gaussian line shapes were used on account of the broader PL signals.

2.6. X-ray Photoelectron Spectroscopy. An Axis Ultra Hybrid (Kratos Analytical) equipped with an Al $\mathrm{K} \alpha$ X-ray source using $10 \mathrm{~mA}$ emission and operating at $15 \mathrm{kV}$ bias was used to obtain photoelectron spectra. Pass energies of 20 and $80 \mathrm{eV}$ were used for high-resolution spectra and survey scans, respectively. The typical vacuum level for measurements was between $2 \times 10^{-8}$ and $3 \times 10^{-8}$ mbar. The spectra were analyzed using CasaXPS software and are calibrated to the $\mathrm{C}$ $1 \mathrm{~s}$ signal of adventitious carbon at $284.8 \mathrm{eV}$.

\section{RESULTS AND DISCUSSION}

We investigated two types of samples: $\mathrm{MoS}_{2}$ flakes produced by MME, which contain a mixture of mono- $(1 \mathrm{~L})$, bi- $(2 \mathrm{~L})$, tri- (3 L), quadri-layer (4 L), and bulk single crystals, as identified by Raman spectroscopy; ${ }^{40}$ and commercially available polycrystalline $1 \mathrm{~L}$ films, produced by CVD. In both cases, $\mathrm{MoS}_{2}$ is deposited onto $\mathrm{SiO}_{2} / \mathrm{Si}$ wafers. The thickness of $1 \mathrm{~L}, 2 \mathrm{~L}$, and $3 \mathrm{~L} \mathrm{MoS}_{2}$ crystals can be determined unambiguously by calculating the frequency difference between the $A_{1 g}$ and $E_{2 g}^{1}$ modes using a well-established procedure based on Raman spectroscopy. ${ }^{40}$ Bulk crystals are easily identified by their optical contrast, while $4 \mathrm{~L}$ thicknesses are assigned to crystals exhibiting an $A_{1 \mathrm{~g}}$ and $E_{2 \mathrm{~g}}^{1}$ frequency difference of $23.8 \mathrm{~cm}^{-1}$, in accordance with previous correlative atomic force microscopy measurements. ${ }^{41}$

For irradiation, $\mathrm{MoS}_{2}$ samples were placed into borosilicate vials and sealed under ambient conditions. Gamma radiation was administered homogeneously throughout the $\mathrm{MoS}_{2}$ samples using gamma photons from a ${ }^{60} \mathrm{Co}$ source. X-ray photoelectron spectroscopy (XPS) was then used to evaluate the radiolytic oxidation of $\mathrm{MoS}_{2}$, while correlative optical microscopy and Raman and PL spectroscopy maps were utilized to gain insights into the radiation-induced changes in the morphology as well as the vibrational and optical properties of $\mathrm{MoS}_{2}$.

3.1. Radiolytic Oxidation of $\mathrm{MoS}_{2}$. Figure 1 shows the deconvoluted S 2p XPS spectra of pristine and irradiated $\mathrm{MoS}_{2}$ crystals, prepared via MME, up to an absorbed dose of 1000 kGy. The $S 2 \mathrm{p}$ spectrum of nonirradiated $\mathrm{MoS}_{2}$ consists of a single doublet, in which the $S 2 \mathrm{p}_{3 / 2}$ and $S 2 \mathrm{p}_{1 / 2}$ photoelectron lines exhibit binding energies of 161.8 and $163.0 \mathrm{eV}$, respectively, corresponding to the $\mathrm{S}^{2-}$ sulfide environment of $\mathrm{MoS}_{2}$ (Figure 1a). After irradiation with an absorbed dose of $100 \mathrm{kGy}$, a second doublet is observed at a higher binding energy in which the $S 2 p_{3 / 2}$ and $S 2 p_{1 / 2}$ photoelectron lines exhibit values of 162.6 and $163.8 \mathrm{eV}$ (Figure $1 \mathrm{~b}$ ). This doublet is attributed to the formation of organosulfur species, which could contain, for example, $\mathrm{S}-\mathrm{O}, \mathrm{S}-\mathrm{C}$, or $\mathrm{S}-\mathrm{H}$ covalent bonds. Photoelectrons originating from this new $S$ environ- 

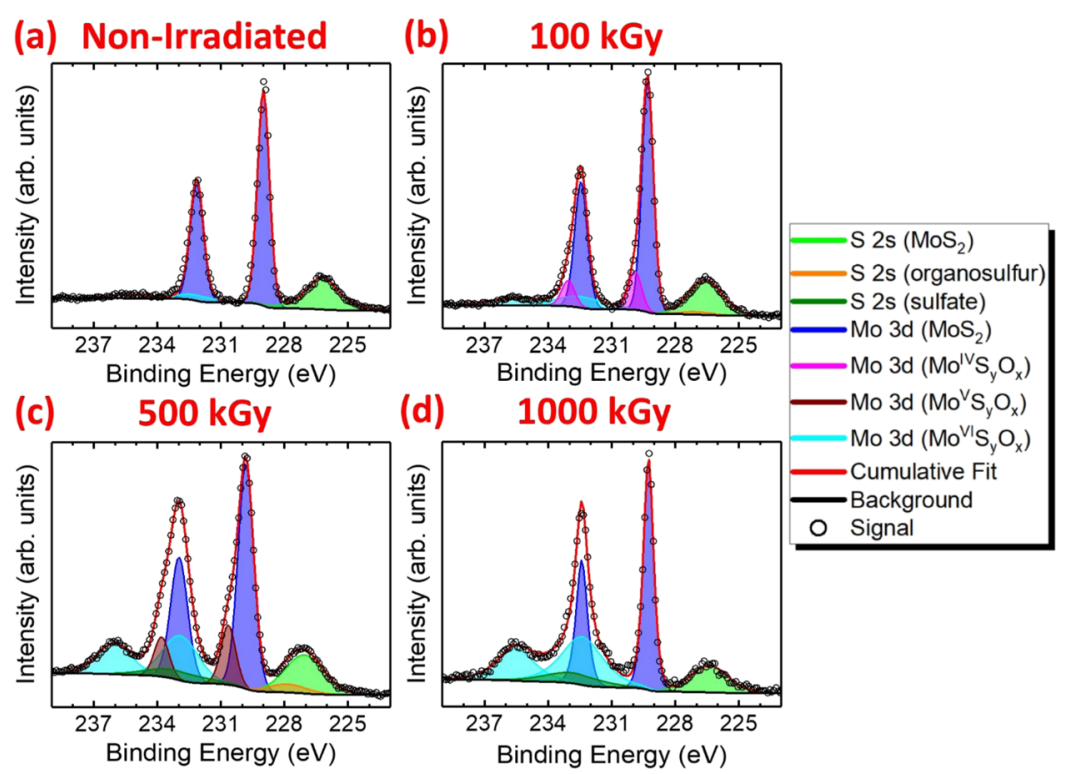

Figure 2. Deconvoluted Mo 3d X-ray photoelectron spectra of $\mathrm{MoS}_{2}$ crystals, deposited by micromechanical exfoliation: (a) prior to irradiation and after irradiation with absorbed doses of (b) $100 \mathrm{kGy}$, (c) $500 \mathrm{kGy}$, and (d) $1000 \mathrm{kGy}$.

ment exhibit lower kinetic energies, i.e., possess higher binding energies, on account of the higher electronegativity of $\mathrm{O}, \mathrm{C}$, and $\mathrm{H}$ atoms relative to $\mathrm{Mo}^{\mathrm{IV}}$ centres. ${ }^{42}$ This results in the organosulfur S 2p core level electrons experiencing a greater effective nuclear charge due to the reduction in the $S$ atom electron density.

Concerning the possible mechanism of organosulfur formation, such compounds could be the stable products of reactions involving $\mathrm{S}$ atoms at the $\mathrm{MoS}_{2}$ crystal surface and the radiolysis products originating from adsorbed water or adventitious carbon, both of which are ubiquitous adsorbates on air-exposed surfaces under ambient conditions. ${ }^{43-45}$ For instance, water radiolysis generates a mixture of highly reactive radical and molecular species, such as the hydrated electron $\left(\mathrm{e}^{-} \mathrm{aq}\right)$, the hydroxyl radical $(\mathrm{OH})$, and hydrogen peroxide $\left(\mathrm{H}_{2} \mathrm{O}_{2}\right) .{ }^{46}$ These species are capable of initiating a plethora of chemical reactions directly involving or affecting $\mathrm{MoS}_{2}$. Moreover, the ionization and excitation of adsorbed hydrocarbons yield reactive carbon-centered radicals. ${ }^{47}$ Subsequent reactions of these species with the $\mathrm{MoS}_{2}$ crystal surface could easily lead to the formation of the observed organosulfur compounds.

Regarding the chemical nature of the organosulfur compounds, the presence of sulfoxide moieties can be ruled out as the binding energy of the $S 2 p_{3 / 2}$ photoelectron line in sulfoxide compounds is $\sim 165.8 \mathrm{eV},{ }^{48,49}$ which is $\sim 3.2 \mathrm{eV}$ higher than the organosulfur $\mathrm{S} 2 \mathrm{p}_{3 / 2}$ signal observed in $\mathrm{MoS}_{2}$ after $100 \mathrm{kGy}$ gamma irradiation (Figure $1 \mathrm{~b}$ ). However, the $S$ $2 p_{3 / 2}$ photoelectron lines of thiol and aliphatic sulfide species exhibit binding energies between 163 and $164 \mathrm{eV}{ }^{49,50}$ This energy range is in reasonable agreement with the value of 162.6 $\mathrm{eV}$ observed for the organosulfur species in Figure $1 \mathrm{~b}$, when taking into account the electropositive influence of the $\mathrm{Mo}^{\mathrm{IV}}$ center(s) still bonded to the $S$ atom. According to the literature, defective $1 \mathrm{LMoS}_{2}$ crystals with $\mathrm{S}$ vacancies at the surface are indeed capable of reacting with organic (1butanethiol) molecules to produce stable crystals containing $\mathrm{Mo}^{\mathrm{IV}}-\mathrm{S}-\mathrm{C}_{4} \mathrm{H}_{9}$ moieties, i.e., the crystal surface is functionalized with alkyl chains. ${ }^{51}$
Interestingly, after administering an absorbed dose of 500 $k G y$, the binding energy of the organosulfur $S 2 p$ core level electrons increases by $0.9 \mathrm{eV}$, such that the $S 2 \mathrm{p}_{3 / 2}$ and $S 2 \mathrm{p}_{1 / 2}$ signals exhibit binding energies of 163.5 and $164.7 \mathrm{eV}$, respectively (Figure 1c). Due to this binding energy increase, the organosulfur photoelectron lines now agree well with the values reported for aliphatic sulfides and thiols, ${ }^{49,50}$ suggesting further $\mathrm{Mo}^{\mathrm{IV}}-\mathrm{S}$ bond scission at higher absorbed doses, i.e., some $\mathrm{S}$ atoms possibly becoming fully detached from the crystal lattice. Moreover, a new doublet is observed in which the $S 2 p_{3 / 2}$ and $S 2 p_{1 / 2}$ photoelectron lines exhibit binding energies of 168.7 and $169.9 \mathrm{eV}$, respectively. These values agree well with those reported for sulfate-containing compounds. ${ }^{52}$ It is reasonable to suggest that the products of water radiolysis, in particular, the strongly oxidizing hydroxyl radical $(\cdot \mathrm{OH})$ and hydrogen peroxide $\left(\mathrm{H}_{2} \mathrm{O}_{2}\right)$, could facilitate the oxidation of $\mathrm{S}$ atoms to produce $\mathrm{SO}_{4}{ }^{2-}$ species.

In addition to the oxidizing species such as $\cdot \mathrm{OH}$ and $\mathrm{H}_{2} \mathrm{O}_{2}$, strongly reducing hydrated electrons, $\mathrm{e}^{-}$aq, are also generated during water radiolysis; the radiation chemical yields of $\cdot \mathrm{OH}$ and $\mathrm{e}^{-}$aq are equal in deaerated water. ${ }^{46}$ In our experiments, one can expect the water layers to be adsorbed on the surface of the $\mathrm{MoS}_{2}$ crystals due to the finite humidity of the atmosphere. Naturally, in the presence of air, the adsorbed water will also contain dissolved oxygen. It is well known that $\mathrm{O}_{2}$ acts as an efficient scavenger for $\mathrm{e}^{-}$aq, yielding the superoxide radical anion via $\mathrm{O}_{2}+\mathrm{e}^{-}$aq $\rightarrow \cdot \mathrm{O}_{2}^{-}$reaction. Although $\cdot \mathrm{O}_{2}{ }^{-}$generally acts as a reducing agent, ${ }^{53}$ its reducing ability is significantly smaller than that of the parent $\mathrm{e}^{-}{ }_{\text {aq }} .54,55$ The atomic hydrogen, $\mathrm{H}$, which is another primary reducing species produced during water radiolysis, ${ }^{54}$ is also readily scavenged by $\mathrm{O}_{2}$ to produce the hydroperoxyl radical via $\mathrm{O}_{2}+$. $\mathrm{H} \rightarrow \cdot \mathrm{O}_{2} \mathrm{H}$ reaction. Due to its $\mathrm{p} K_{\mathrm{a}}$ value of 4.8 , in neutral aqueous media, $\cdot \mathrm{O}_{2} \mathrm{H}$ will exist mostly as $\cdot \mathrm{O}_{2}{ }^{-}$through the equilibrium: $\cdot \mathrm{O}_{2} \mathrm{H}+\mathrm{OH}^{-} \rightleftharpoons \mathrm{O}_{2}{ }^{-}+\mathrm{H}_{2} \mathrm{O}$.

In essence, primary strongly reducing species from water radiolysis become rapidly scavenged by $\mathrm{O}_{2}$ to yield weakly reducing $\cdot \mathrm{O}_{2}^{-}$species, creating overall oxidizing conditions (note that the $\mathrm{OH}$ and $\mathrm{H}_{2} \mathrm{O}_{2}$ remain available for reacting with 
$\mathrm{MoS}_{2}$ ), thus promoting the oxidation of sulfur atoms in $\mathrm{MoS}_{2}$. This process is expected to proceed through a sequence of electron donations since the oxidation state of the sulfur atom needs to change, eventually, from -2 to +6 . For such extensive oxidation to occur, large absorbed doses of radiation would be required. Indeed, in our experiments, the formation of sulfate species becomes observable only after irradiation with an absorbed dose of $500 \mathrm{kGy}$ and is attributed to the cumulative effect of oxidation reactions between $\mathrm{OH}, \mathrm{H}_{2} \mathrm{O}_{2}$, and the $\mathrm{S}$ atoms as well as the aliphatic sulfides/thiols produced at the earlier stages of radiolysis. In good accordance with our studies, Lefticariu et al. unambiguously observed sulfate formation in aqueous systems containing $\mathrm{FeS}_{2}$, which they attributed to oxidation reactions involving the products of water radiolysis. $^{56}$

After an absorbed dose of $1000 \mathrm{kGy}$ is administered to the $\mathrm{MoS}_{2}$ crystals, the organosulfur $\mathrm{S} 2 \mathrm{p}$ doublet is no longer observed (Figure 1d). This is accompanied by a significant increase in the integrated intensity of the sulfate doublet relative to the $\mathrm{S}^{2-}$ environment. This is expected since the C$\mathrm{S}$ bond cleavage and photooxygenation of aliphatic sulfides/ thiols $^{57}$ are mediated by the products of water radiolysis to result in sulfate species being a prevailing oxidation product at higher absorbed doses. Therefore, sulfate species represent the final product of $S$ atom oxidation, with the organosulfur compounds being intermediates. The sampling depth of the Al $\mathrm{K} \alpha \mathrm{X}$-ray source utilized for XPS measurements is $\sim 6 \mathrm{~nm},{ }^{58,59}$ corresponding to the uppermost $\sim 8 \mathrm{MoS}_{2}$ monolayers without accounting for adsorbates. Therefore, the absence of organosulfur intermediates and the increased concentration of sulfate species suggest extensive oxidation of the $\mathrm{MoS}_{2}$ crystal surface upon irradiation with a large absorbed dose of $1000 \mathrm{kGy}$.

Figure 2 shows the deconvoluted Mo 3d XPS spectra of pristine and irradiated $\mathrm{MoS}_{2}$ crystals, prepared via MME, up to an absorbed dose of $1000 \mathrm{kGy}$. The Mo 3d spectrum of nonirradiated crystals consists of one singlet and one doublet in which the $S 2 \mathrm{~s}$, Mo $3 \mathrm{~d}_{5 / 2}$, and Mo $3 \mathrm{~d}_{3 / 2}$ photoelectron lines, corresponding to the $\mathrm{S}^{2-}$ and $\mathrm{Mo}^{\mathrm{IV}}$ environments of $\mathrm{MoS}_{2}$, exhibit binding energies of 226.2, 229.0, and $232.1 \mathrm{eV}$, respectively (Figure 2a). After irradiation with an absorbed dose of $100 \mathrm{kGy}$, the formation of a second doublet is observed at a higher binding energy in which the Mo $3 \mathrm{~d}_{5 / 2}$ and Mo $3 \mathrm{~d}_{3 / 2}$ photoelectron lines exhibit values of 229.9 and $233.1 \mathrm{eV}$ (Figure 2b). This doublet is attributed to the formation of $\mathrm{Mo}^{\mathrm{IV}} \mathrm{S}_{y} \mathrm{O}_{x}$ species, i.e., formation of $\mathrm{Mo}-\mathrm{O}$ bonds where $\mathrm{O}^{2-}$ replaces $\mathrm{S}^{2-}$, but the oxidation state of the Mo center remains +4 . The binding energy of the Mo $3 \mathrm{~d}_{5 / 2}$ photoelectron signal is in good agreement with that reported for $\mathrm{MoO}_{2} ;{ }^{60}$ however, as the exact stoichiometry of the oxidized $\mathrm{Mo}^{\mathrm{IV}}$ product is hard to deduce, the general formula $\mathrm{Mo}^{\mathrm{IV}} \mathrm{S}_{y} \mathrm{O}_{x}$ is assigned to this species in our work.

The mechanism of the Mo-O bond formation is likely to proceed via the displacement of $\mathrm{S}$ atoms from their lattice sites due to elastic collisions involving energetic recoil electrons from the Compton scattering of gamma photons. Calculated recoil electron energies, as a function of the scattering angle, suggest that the production of $S$ vacancies is energetically feasible when using a ${ }^{60} \mathrm{Co}$ source (Figure S1a, Supporting Information). Furthermore, the normalized differential crosssection dictates that $\sim 68 \%$ of all recoil electrons produced during the Compton scattering will have sufficient kinetic energy to displace $S$ atoms from their lattice sites (Figure $S 1 b$, Supporting Information).
Density functional theory calculations show that when atmospheric $\mathrm{O}_{2}$ molecules are adsorbed onto $\mathrm{S}$ vacancies, the activation energy barrier for $\mathrm{O}_{2}$ dissociation is lowered, which could facilitate $\mathrm{Mo}-\mathrm{O}$ bond formation. ${ }^{61}$ In addition to spontaneous $\mathrm{O}_{2}$ dissociation, the ionization of adsorbed $\mathrm{O}_{2}$ due to the Compton scattering will produce highly reactive . $\mathrm{O}_{2}{ }^{+}$species. ${ }^{62}$ Moreover, reactions between $\mathrm{Mo}^{\mathrm{IV}}$ centers, bearing vacant coordination sites, and $\cdot \mathrm{OH}$ and $\mathrm{H}_{2} \mathrm{O}_{2}$ species, formed during water radiolysis, may also contribute toward $\mathrm{Mo}-\mathrm{O}$ bond formation. Indeed, passivation of $\mathrm{S}$ vacancies in defective $\mathrm{MoS}_{2}$ via inclusion of $\mathrm{O}$ atoms from $\mathrm{H}_{2} \mathrm{O}_{2}$ has been observed experimentally. ${ }^{63}$

After irradiation with an absorbed dose of $500 \mathrm{kGy}$, the binding energy of the $\mathrm{Mo}^{\mathrm{IV}} \mathrm{S}_{y} \mathrm{O}_{x}$ doublet further increases by $\sim 0.7 \mathrm{eV}$ such that the Mo $3 \mathrm{~d}_{5 / 2}$ and Mo $3 \mathrm{~d}_{3 / 2}$ photoelectron lines exhibit binding energies of 230.7 and $233.8 \mathrm{eV}$, respectively (Figure $2 \mathrm{c}$ ). The magnitude of this binding energy increase suggests that $\mathrm{Mo}^{\mathrm{IV}}$ centers undergo further oxidation to yield $\mathrm{Mo}^{\mathrm{V}} \mathrm{S}_{y} \mathrm{O}_{x}$ species. Indeed, the binding energies observed in this work agree well with those observed for $\mathrm{Mo}^{\mathrm{V}}$ centers in oxysulfide thin films. ${ }^{64}$ Moreover, the integrated intensity of a third Mo $3 \mathrm{~d}$ doublet becomes considerable after irradiation with an absorbed dose of 500 $\mathrm{kGy}$. The doublet exhibiting Mo $3 \mathrm{~d}_{5 / 2}$ and Mo $3 \mathrm{~d}_{3 / 2}$ binding energies of 232.9 and $236.1 \mathrm{eV}$, respectively, is attributed to the formation of $\mathrm{Mo}^{\mathrm{VI}} \mathrm{S}_{y} \mathrm{O}_{x}$ species. These binding energies match well with those reported for $\mathrm{MoO}_{3}{ }^{65,66}$ Since the exact stoichiometry of the oxidized $\mathrm{Mo}^{\mathrm{VI}}$ species is difficult to deduce, the general formula $\mathrm{Mo}^{\mathrm{VI}} \mathrm{S}_{y} \mathrm{O}_{x}$ is used to denote this oxidized product. In addition to the formation of the oxidized $\mathrm{Mo}^{\mathrm{V}}$ and $\mathrm{Mo}^{\mathrm{VI}}$ species, two singlet photoelectron lines are observed at 227.9 and $233.1 \mathrm{eV}$, corresponding to the binding energies of the organosulfur and sulfate $S 2 s$ core level electrons, respectively.

Akin to the absence of the organosulfur photoelectron lines in the S 2p XPS spectrum of $\mathrm{MoS}_{2}$ irradiated with an absorbed dose of $1000 \mathrm{kGy}$, no $\mathrm{Mo}^{\mathrm{V}} \mathrm{S}_{y} \mathrm{O}_{x}$ species are observed in the corresponding Mo 3d spectrum (Figure 2d). Equivalent to sulfate formation, the oxidation of Mo atoms to $\mathrm{Mo}^{\mathrm{VI}} \mathrm{S}_{y} \mathrm{O}_{x}$ and $\mathrm{MoO}_{3}$ represents the final product of $\mathrm{MoS}_{2}$ oxidation.

Similar to how organosulfur intermediates appear to be formed via reactions involving the products of adventitious carbon radiolysis, it is possible that $\mathrm{Mo}^{\mathrm{V}} \mathrm{S}_{y} \mathrm{O}_{x}$ intermediates may be the product of reactions between $S$ vacancies and either water radiolysis products and/or oxygen. This hypothesis was tested by irradiating $\mathrm{MoS}_{2}$ crystals, fabricated by MME, with a moderate absorbed dose of $100 \mathrm{kGy}$, after the sample had been conditioned in a constant humidity chamber for 5 days at $95 \%$ relative humidity prior to irradiation. The deconvoluted XPS spectra (Figures S2 and S3, Supporting Information) indeed show strongly enhanced formation of $\mathrm{Mo}^{\mathrm{V}} \mathrm{S}_{y} \mathrm{O}_{x}$ in this sample proving that the $\mathrm{Mo}^{\mathrm{V}} \mathrm{S}_{y} \mathrm{O}_{x}$ species is an important oxidation intermediate produced via the reaction of $\mathrm{MoS}_{2}$ surface atoms with the oxidizing products from water radiolysis. This result also highlights an important role which water plays in the acceleration of the radiolytic oxidation of $2 \mathrm{D}$ $\mathrm{MoS}_{2}$.

Finally, to assess the effect of crystal morphology on the radiolytic processes in $\mathrm{MoS}_{2}$, polycrystalline $1 \mathrm{~L} \mathrm{CVD} \mathrm{films} \mathrm{of}$ $\mathrm{MoS}_{2}$ were irradiated with absorbed doses between $40 \mathrm{kGy}$ and $150 \mathrm{kGy}$. Their XPS spectra are shown in Figures S4 and S5, Supporting Information. In these samples, extensive oxidation of $\mathrm{MoS}_{2}$, resulting in $\mathrm{Mo}^{\mathrm{VI}} \mathrm{S}_{y} \mathrm{O}_{x}$ and sulfate 
(a) Non-Irradiated

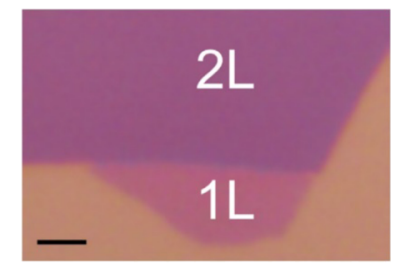

(d)

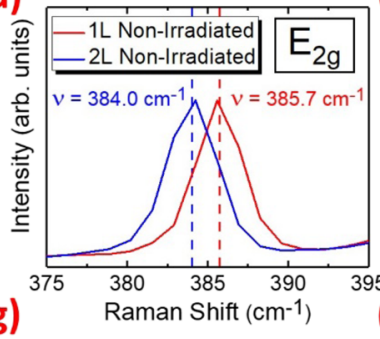

(g)

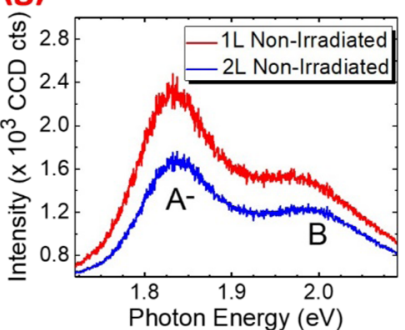

(b) $500 \mathrm{kGy}$

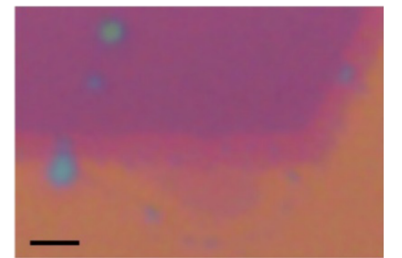

${ }^{(e)}{ }_{2 g}$ Frequency

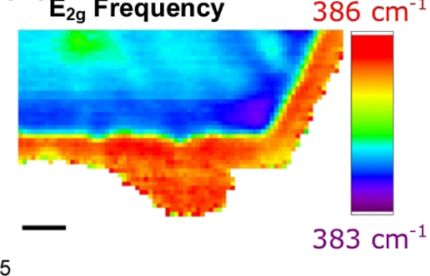

(h) (c) $1000 \mathrm{kGy}$

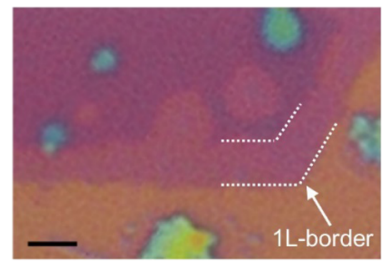

(f)

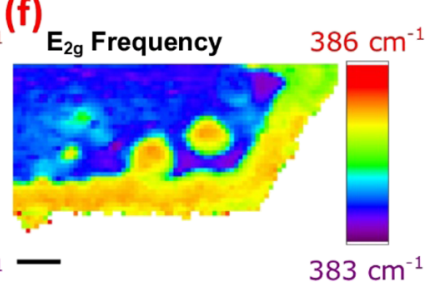

(i)

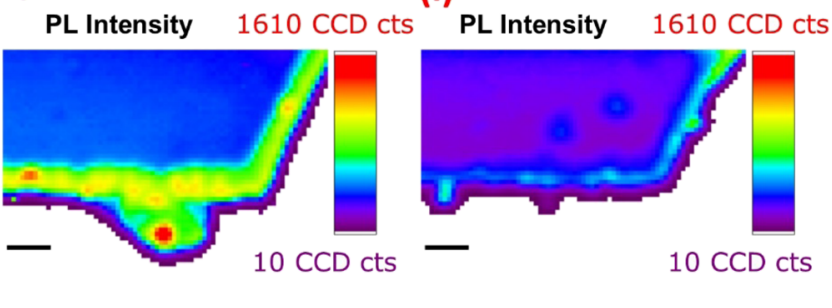

Figure 3. Top row: Optical micrographs of monolayer ( $1 \mathrm{~L}$ ) and bilayer $(2 \mathrm{~L})$ crystals, produced by micromechanical exfoliation, (a) prior to irradiation and after irradiation with absorbed doses of (b) $500 \mathrm{kGy}$ and (c) $1000 \mathrm{kGy}$. Middle row: (d) Raman spectra of nonirradiated $\mathrm{MoS}_{2}$ crystals showing a blue shift of the in-plane $E_{2 g}^{1}$ mode when the thickness decreases from $2 \mathrm{~L}$ (blue) to $1 \mathrm{~L}$ (red) and correlative Raman maps of the $1 \mathrm{~L}$ and $2 \mathrm{~L}$ domains visible in the optical micrographs showing the variation of the $E_{2 \mathrm{~g}}^{1}$ frequency across the crystals after irradiation with absorbed

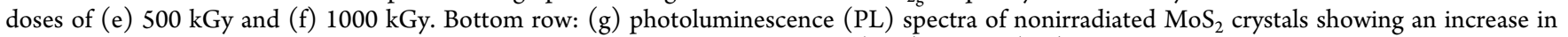
the $\mathrm{A}^{-}$trion and $\mathrm{B}$ exciton intensities when the thickness decreases from $2 \mathrm{~L}$ (blue) to $1 \mathrm{~L}$ (red) and correlative PL maps of the $1 \mathrm{~L}$ and $2 \mathrm{~L}$ domains visible in the optical micrographs showing the variation of the PL intensity across the crystals after irradiation with absorbed doses of (h) $500 \mathrm{kGy}$ and (i) $1000 \mathrm{kGy}$. All scale bars correspond to a length of $2 \mu \mathrm{m}$.

formation, is observed even within the low-dose regime, contrasting the results obtained for MME samples, which showed much milder oxidation under the same doses. This difference is attributed to the polycrystalline morphology of the 1 L CVD films, i.e., they contain a greater number of active edge sites and grain boundaries relative to their predominantly single-crystal MME counterparts. An important role of the active edge sites in the radiolytic transformation of $\mathrm{MoS}_{2}$ crystals is discussed in detail next.

3.2. Radiation Effects on $\mathrm{MoS}_{2}$ Morphology. Concerning the effects of high-dose gamma irradiation on the morphology of $2 \mathrm{D} \quad \mathrm{MoS}_{2}$ produced by MME, Figure 3a shows an optical micrograph of $1 \mathrm{~L}$ and $2 \mathrm{~L}$ crystals prior to irradiation. Differentiation between the $\mathrm{SiO}_{2}$ substrate and the $1 \mathrm{~L} / 2 \mathrm{~L} \mathrm{MoS}_{2}$ regions is facile on account of the distinct optical contrast and sharp, well-defined edges of the crystals. After irradiation with an absorbed dose of $500 \mathrm{kGy}$, the size of the $1 \mathrm{~L}$ crystal domain is significantly reduced (Figure $3 \mathrm{~b}$ ).

Moreover, the optical contrast of the $2 \mathrm{~L}$ domain is considerably lower at the periphery of the crystal, such that it resembles the contrast of the $1 \mathrm{~L}$ crystal prior to irradiation. In other words, after irradiation, the surface of the $2 \mathrm{~L}$ crystal appears to be "etched", yielding $1 \mathrm{~L} \mathrm{MoS}_{2}$. These findings suggest that the edges of the uppermost layers in $\mathrm{MoS}_{2}$ crystals are more susceptible to radiation damage, resulting in observed reduction in the lateral dimensions of $1 \mathrm{~L}$ crystals and the formation of a " $1 \mathrm{~L}$ border" in $2 \mathrm{~L}$ crystals.
The higher susceptibility of edge and surface atoms toward radiation damage could be attributed to the high reactivity of edge defects as well as the spatial confinement of adsorbates. More precisely, the concentration of vacant coordination sites, localized at the edges of $\mathrm{MoS}_{2}$ crystals, has been correlated with the catalytic efficiency of $\mathrm{MoS}_{2}$ in the hydrogen evolution reaction. ${ }^{67,68}$ If such active edge sites exhibit higher reactivity than their basal plane counterparts, it follows that the rate of reactions involving the products of adsorbate radiolysis could also be significantly higher at the edges of $\mathrm{MoS}_{2}$ crystals.

$1 \mathrm{~L} \mathrm{MoS}_{2}$ crystals are just $0.7 \mathrm{~nm}$ thick. Hence, they are visible via optical microscopy only when deposited on substrates with discrete dielectric thicknesses. In this work, $\mathrm{MoS}_{2}$ crystals are deposited on top of $300 \mathrm{~nm}$ thick quartzcoated silicon wafers. Consequently, the optical contrast of deposited 2D MoS 2 crystals is significantly increased due to multiple reflections at various interfaces, ${ }^{69}$ and $1 \mathrm{~L}$ crystals become easily visible (Figure 3a). Upon exposure to gamma irradiation, the active edge sites of $1 \mathrm{~L} \mathrm{MoS}_{2}$ crystals react with the products of adsorbate radiolysis, yielding oxidized intermediates and, eventually, $\mathrm{Mo}^{\mathrm{VI}} \mathrm{S}_{y} \mathrm{O}_{x}$ and sulfate species, as discussed earlier. In contrast, these oxidized products are not visible via optical microscopy as they are formed in the amorphous state. As the crystalline interface becomes more disordered, fewer reflections are possible, leading to a significant reduction in optical contrast. Hence, the $1 \mathrm{~L}$ crystal domain size appears to "shrink" (Figure 3b). Moreover, the 
(a)

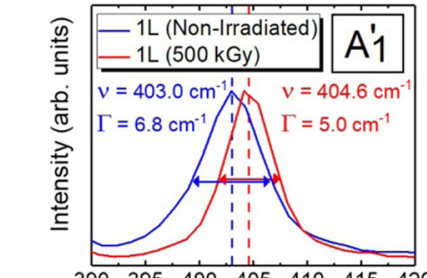

(d)

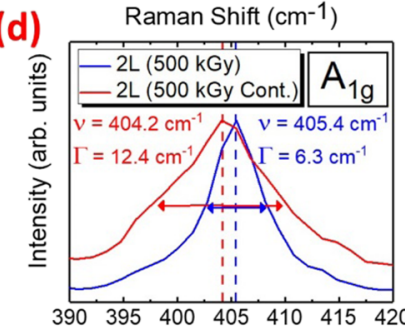

(g)
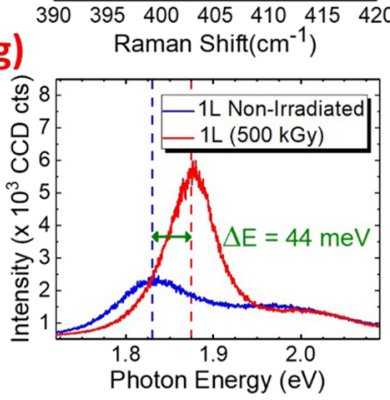

(b) 500 kGy

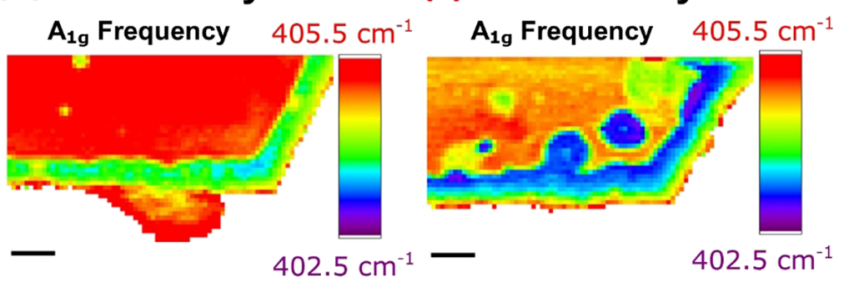

(e)

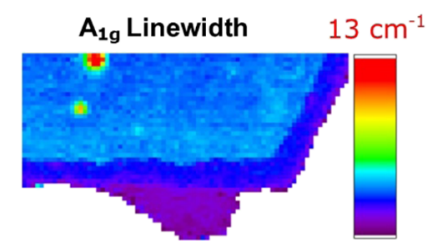

(h) (f)

(c) $1000 \mathrm{kGy}$

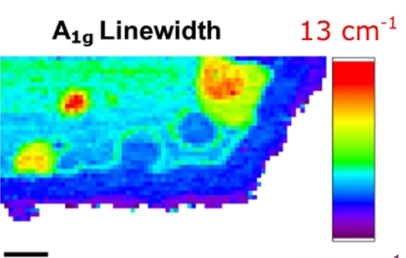

$4.0 \mathrm{~cm}^{-1}$

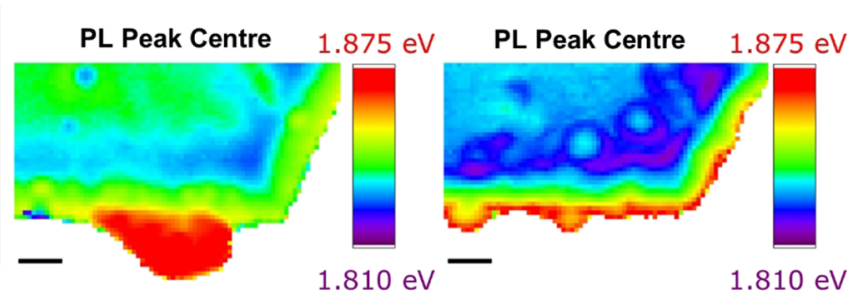

(i)
$4.0 \mathrm{~cm}^{-1}$

Figure 4. Top row: (a) Raman spectra of the $1 \mathrm{~L} \mathrm{MoS}_{2}$ crystal domain prior to irradiation (blue) and after irradiation with an absorbed dose of 500 $\mathrm{kGy}(\mathrm{red})$ showing an increase in the frequency $(v)$ and reduction in the line width $(\Gamma)$ of the out-of-plane $A_{1}^{\prime}$ mode. Correlative Raman maps of the $1 \mathrm{~L}$ and $2 \mathrm{~L}$ domains visible in the optical micrographs showing the variation of the $A_{1 \mathrm{~g}}$ frequency across the crystals after irradiation with absorbed doses of (b) $500 \mathrm{kGy}$ and (c) $1000 \mathrm{kGy}$. Middle row: (d) Raman spectra of the $2 \mathrm{~L}$ domain after irradiation with an absorbed dose of 500 $\mathrm{kGy}$ showing a decrease in the $v$ and an increase in the $\Gamma$ of the $A_{\mathrm{gg}}$ mode when the crystal is contaminated (Cont.) with carbonaceous aggregates (red) relative to the uncontaminated $2 \mathrm{~L}$ region (blue). Correlative Raman maps of the $1 \mathrm{~L}$ and $2 \mathrm{~L}$ domains visible in the optical micrographs showing the variation of the $A_{1 \mathrm{~g}}$ line width across the crystals after irradiation with absorbed doses of (e) $500 \mathrm{kGy}$ and (f) $1000 \mathrm{kGy}$. Bottom row: (g) Photoluminescence (PL) spectra of the $1 \mathrm{~L} \mathrm{MoS}_{2}$ domain showing a blue shift and an increase in the PL intensity when the crystal is irradiated with an absorbed dose of $500 \mathrm{kGy}$ (red) relative to the same region prior to irradiation (blue). Correlative PL maps of the $1 \mathrm{~L}$ and $2 \mathrm{~L}$ domains visible in the optical micrographs showing the variation of the PL peak center across the crystals after irradiation with absorbed doses of (h) 500 $\mathrm{kGy}$ and (i) $1000 \mathrm{kGy}$. All scale bars correspond to a length of $2 \mu \mathrm{m}$.

spatial distribution of adsorbates is such that they are confined to the surface, i.e., the uppermost layer of the $\mathrm{MoS}_{2}$ crystal. Therefore, the rate of reaction between the products of adsorbate radiolysis and the bottom layer of the $2 \mathrm{~L} \mathrm{MoS}_{2}$ crystal would be considerably lower due to the barrier of amorphous products formed during the oxidation of the top layer of the $2 \mathrm{~L}$ crystal. A combination of these processes is likely to be responsible for the appearance of a $1 \mathrm{~L}$-border after irradiation with an absorbed dose of $500 \mathrm{kGy}$ (Figure 3b).

Furthermore, in the optical micrograph of the same $1 \mathrm{~L}$ and $2 \mathrm{~L}$ crystals after irradiation with an absorbed dose of 1000 $\mathrm{kGy}$, three circular regions appear in the $2 \mathrm{~L}$ crystal domain, exhibiting significantly reduced optical contrast (Figure 3c). This observation suggests that holes have been etched in the uppermost $\mathrm{MoS}_{2}$ layer of the $2 \mathrm{~L}$ crystal. The formation of these circular features indicates a transition to nonselective radiolytic etching in $\mathrm{MoS}_{2}$ crystals irradiated with absorbed doses greater than $500 \mathrm{kGy}$. The loss of selectivity could be attributed to the stochastic spatial distribution of native vacancies $^{70}$ and those produced by elastic collisions involving energetic recoil electrons. Such vacancies within the basal plane of $\mathrm{MoS}_{2}$ would serve as reaction centers due to the introduction of vacant coordination sites. ${ }^{23}$ Hence, as reactions involving the products of adsorbate radiolysis proceed, radiolytic etching of the uppermost layer could emanate outwards, creating a "circle" in a similar fashion to the etching propagating inwards from the crystal edges, creating a "1 Lborder." Aside from the loss of selectivity, it should also be noted that upon irradiation with $1000 \mathrm{kGy}$ : (1) the $1 \mathrm{~L}$ crystal is no longer visible, i.e., it is completely etched, (2) no circular holes are etched in the bottom layer of the $2 \mathrm{~L}$ crystal, and (3) the diameter of $1 \mathrm{~L}$-border increases from $\sim 1.4$ to $\sim 2 \mu \mathrm{m}$.

Prior to irradiation, the optical contrast is essentially invariant within the $1 \mathrm{~L} / 2 \mathrm{~L}$ domains and across the substrate (Figure 3a). However, upon irradiation with an absorbed dose of $500 \mathrm{kGy}$, numerous circular features exhibiting distinct optical contrast are observed on the surface of the sample (Figure $3 b$ ). Moreover, the diameter and number of the circular features increase when irradiated with $1000 \mathrm{kGy}$ (Figure 3c). Importantly, similar features have been observed on the surface of gamma-irradiated few-layer $\mathrm{MoS}_{2}$ films in the past. $^{38}$ To assess whether these circular features are aggregates containing products of $\mathrm{MoS}_{2}$ radiolysis, a pristine $\mathrm{SiO}_{2} / \mathrm{Si}$ wafer was irradiated with a dose of $391 \mathrm{kGy}$ in the absence of $\mathrm{MoS}_{2}$ crystals. Optical micrographs show that circular features with similar contrast and morphology are formed on the $\mathrm{SiO}_{2}$ surface after gamma irradiation (Figure S6, Supporting Information). Therefore, we conclude that the chemical 
composition of these features is likely to be organic and formed via radiolytic reactions involving adventitious carbon and/or adsorbed water. They are herein referred to as "carbonaceous aggregates."

Figure $3 \mathrm{~d}$ shows the Raman signal corresponding to the inplane $E_{2 \mathrm{~g}}^{1}$ normal vibrational mode of the pristine $1 \mathrm{~L}$ and $2 \mathrm{~L}$ $\mathrm{MoS}_{2}$ crystals visualized by optical microscopy. The frequency of the $E_{2 \mathrm{~g}}^{1}$ mode is observed to blue shift when the thickness of the $\mathrm{MoS}_{2}$ crystal decreases from $2 \mathrm{~L}$ to $1 \mathrm{~L}$, in accordance with the literature. ${ }^{40}$ The blue shift is attributed to an increase in the surface force constant caused by a slight charge redistribution due to the absence of an adjacent $\mathrm{MoS}_{2}$ layer. ${ }^{71,72}$ We utilized this characteristic spectroscopic distinction to further confirm the etching of $\mathrm{MoS}_{2}$ crystals under gamma irradiation. In particular, Raman spectroscopy maps are used in this work to evaluate the variation of the $E_{2 \mathrm{~g}}^{1}$ frequency across the $1 \mathrm{~L}$ and 2 $\mathrm{L} \mathrm{MoS}_{2}$ crystals after irradiation. Indeed, after irradiation with an absorbed dose of $500 \mathrm{kGy}$, the periphery of the $2 \mathrm{~L}$ crystal exhibits a significant blue shift of the $E_{2 g}^{1}$ mode relative to the center of the $2 \mathrm{~L}$ domain (Figure $3 \mathrm{e}$ ). Moreover, the average frequency of the in-plane $E^{\prime}$ mode exhibited by the $1 \mathrm{~L}$-border agrees well with the $1 \mathrm{~L}$ crystal present prior to irradiation. Hence, edge-selective radiolytic etching of $2 \mathrm{~L} \mathrm{MoS}_{2}$ to yield 1 $\mathrm{L}$ domains has been unambiguously confirmed.

Upon irradiation with an absorbed dose of $1000 \mathrm{kGy}$, the Raman signal originating from the $1 \mathrm{~L}$ domain present prior to irradiation becomes negligible, thus confirming that the crystal has been etched completely (Figure 3f). The three circular features identified by optical microscopy exhibit a considerable blue shift of the $E_{2 g}^{1}$ mode such that they agree well with the values observed within the surrounding 1 L-border, i.e., the loss of edge-selective radiolytic etching in $2 \mathrm{~L}$ crystals irradiated with the high absorbed doses is also confirmed.

Figure $3 \mathrm{~g}$ shows the PL spectra of the pristine $2 \mathrm{~L}$ and $1 \mathrm{~L}$ $\mathrm{MoS}_{2}$ crystals visualized by optical microscopy. The typical PL spectrum of $\mathrm{MoS}_{2}$ consists of neutral A and $\mathrm{B}$ excitons observed at $\sim 1.90$ and $\sim 2.05 \mathrm{eV}$, respectively. ${ }^{6}$ However, due to the deposition of the $2 \mathrm{D} \mathrm{MoS}$ crystals onto $\mathrm{SiO}_{2}$, charge transfer from the substrate indicates that the $\mathrm{A}$ exciton exists as a negatively charged trion $\left(\mathrm{A}^{-}\right)$observed at $\sim 1.83 \mathrm{eV}$ (Figure $3 \mathrm{~g}) .^{73}$ The optical properties of $2 \mathrm{D} \mathrm{MoS}$ crystals are known to be strongly dependent on the crystal thickness. ${ }^{74}$ As mentioned earlier, an indirect-direct band gap transition is observed when $2 \mathrm{~L} \mathrm{MoS}_{2}$ crystals are thinned to $1 \mathrm{~L}^{5}$ The increased PL intensity of the $1 \mathrm{~L}$ crystal, relative to the $2 \mathrm{~L}$ domain, is attributed to the higher PL quantum efficiency of $1 \mathrm{~L} \mathrm{MoS}_{2}$ due to its direct band gap (Figure $3 \mathrm{~g}$ ). Correspondingly, the $\mathrm{PL}$ intensity at the periphery of the $2 \mathrm{~L}$ crystal is increased relative to the internal region of the $2 \mathrm{~L}$ domain after $500 \mathrm{kGy}$ irradiation (Figure 3h). This observation corroborates the conclusions reached via optical microscopy and Raman spectroscopy, outlined earlier, and further supports the hypothesis that the edge-selective radiolytic etching of the uppermost layer in $2 \mathrm{~L} \mathrm{MoS}_{2}$ yields a $1 \mathrm{~L}$ domain at the periphery of the crystal, i.e., the formation of a 1 L-border. However, the PL intensity of the 1 L-border decreases significantly upon irradiation with an absorbed dose of 1000 $\mathrm{kGy}$ (Figure 3i). This is attributed to the formation of midgap states, introduced by defects, which increase the number of nonradiative decay pathways and lead to the observed reduction in the PL quantum yield. ${ }^{23}$ Moreover, it should be noted that radiolytic etching is not limited to $2 \mathrm{~L}$ crystals yielding $1 \mathrm{~L}$ domains. Etching of $3 \mathrm{~L}$ and $4 \mathrm{~L}$ crystals has also been observed and investigated by correlative optical microscopy and Raman/PL spectroscopy maps; see the discussion and Figures S7-S11 in the Supporting Information. In addition, the full Raman spectra of $1 \mathrm{~L}$ crystals (pristine and $500 \mathrm{kGy})$ and the $1 \mathrm{~L}$ border region $(500 \mathrm{kGy})$ are available in Figure S12, Supporting Information.

3.3. Radiation-Induced Doping of $\mathrm{MoS}_{2}$. In addition to the changes in the chemical composition and morphology of the crystals under gamma irradiation, correlative optical microscopy and Raman and PL spectroscopy maps have been used to gain insights into the doping mechanisms of 2D $\mathrm{MoS}_{2}$ irradiated within the highly absorbed dose regime (Figure 4). The maps shown in Figure 4 are obtained from the same $1 \mathrm{~L}$ and $2 \mathrm{~L}$ crystals shown in the optical micrographs in Figure 3, after irradiation with an absorbed dose of $500 \mathrm{kGy}$ (Figures $3 b$ and $4 b, e, h$ ) and 1000 kGy (Figures $3 c$ and $4 c, f, i$ ). The optical micrographs can be utilized to aid spatial correlation between crystal domains and changes in their vibrational and optical properties.

Figure $4 \mathrm{a}$ shows the Raman signal of the pristine $1 \mathrm{~L} \mathrm{MoS}_{2}$ domain corresponding to the out-of-plane $A_{1}^{\prime}$ normal vibrational mode, which exhibits a frequency and line width of 403.0 and $6.8 \mathrm{~cm}^{-1}$, respectively. Upon irradiation with an absorbed dose of $500 \mathrm{kGy}$, the $A_{1}^{\prime}$ mode of the $1 \mathrm{~L}$ crystal exhibits a $1.6 \mathrm{~cm}^{-1}$ blue shift, while the line width decreases by $1.8 \mathrm{~cm}^{-1}$. The frequency and line width of the $A_{1}^{\prime}$ mode in $1 \mathrm{~L}$ $\mathrm{MoS}_{2}$ are known to be strongly modulated by doping, ${ }^{75}$ and the observed changes indicate that $1 \mathrm{~L} \mathrm{MoS}_{2}$ becomes $\mathrm{p}$ doped $^{23}$ after $500 \mathrm{kGy}$ irradiation.

Regarding the mechanism of gamma radiation-induced $\mathrm{p}$ doping, the efficiency of charge transfer between oxygen and 1 $\mathrm{L} \mathrm{MoS}_{2}$ increases when $\mathrm{O}_{2}$ is adsorbed onto $\mathrm{S}$ vacancies, as opposed to the pristine basal plane of the crystal. ${ }^{76}$ Such vacancies can be introduced into the lattice via elastic collisions involving energetic recoil electrons. When $\mathrm{O}_{2}$ adsorbs onto radiation-induced vacancies, charge-transfer interactions lead to a lowering of the Fermi level, i.e., $\mathrm{MoS}_{2}$ becomes p-doped.

Moreover, the out-of-plane $A_{1}^{\prime}$ phonons retain the symmetry of the $\mathrm{MoS}_{2}$ lattice; hence, they couple strongly with electrons. ${ }^{75}$ Therefore, as p-doping is expected to decrease the amount of electrons occupying antibonding states in the conduction band of $1 \mathrm{~L} \mathrm{MoS}_{2}$, this results in an increase in the force constant of the out-of-plane vibration, i.e., the $A_{1}^{\prime}$ mode blue shifts. Regarding the reduction in the line width of the $A_{1}^{\prime}$ mode, this is a direct consequence of the electron-phonon coupling, i.e., the line width of a Raman signal is influenced by both the lifetime of a phonon and how strongly it couples to electrons. ${ }^{75}$ Indeed, p-type changes to the Raman spectrum of defective 2D $\mathrm{MoS}_{2}$ have been observed previously and attributed to charge-transfer interactions involving adsorbed oxygen. $^{23}$

Figure $4 \mathrm{~b}$ shows the variation of the $A_{1 \mathrm{~g}}$ frequency across the $1 \mathrm{~L}$ and $2 \mathrm{~L}$ crystals after irradiation with an absorbed dose of $500 \mathrm{kGy}$. The $A_{1}^{\prime}$ frequency of the 1 L-border produced by edge-selective radiolytic etching is blue shifted by approximately $1 \mathrm{~cm}^{-1}$ relative to the value measured for pristine $1 \mathrm{~L}$ $\mathrm{MoS}_{2}$ prior to irradiation. This is in contrast to the p-doped 1 $\mathrm{L}$ domain present prior to irradiation, i.e., not produced by etching, which exhibits a more pronounced $1.6 \mathrm{~cm}^{-1}$ shift, as previously outlined (Figure 4a). Indeed, upon irradiation with an absorbed dose of $1000 \mathrm{kGy}$, the $A_{1}^{\prime}$ frequency at the periphery of the 1 L-border remains blue shifted by approximately $1 \mathrm{~cm}^{-1}$ (Figure $4 \mathrm{c}$ ). However, the blue shift 
within the central region of the $1 \mathrm{~L}$-border is $<1 \mathrm{~cm}^{-1}$, i.e., not statistically significant. Therefore, a possibility of $\mathrm{p}$-doping of 1 $\mathrm{L} \mathrm{MoS}_{2}$ domains created by radiolytic etching would require further investigation.

Figure $4 \mathrm{~d}$ shows the Raman signal corresponding to the $A_{1 \mathrm{~g}}$ mode of the $2 \mathrm{~L} \mathrm{MoS}_{2}$ crystal irradiated with an absorbed dose of $500 \mathrm{kGy}$. Two distinct Raman shift values are observed in the spectra. The first one is acquired from a surface region of the $2 \mathrm{~L}$ crystal, which is contaminated with carbonaceous aggregates, while the other is acquired from a neighboring uncontaminated region. A significant red shift and line width increase of the $A_{\mathrm{lg}}$ mode is observed when carbonaceous aggregates are adsorbed on $2 \mathrm{~L} \mathrm{MoS}_{2}$ crystals. Indeed, the spatial distribution of the aggregates, observed in the optical micrographs of $\mathrm{MoS}_{2}$ crystals irradiated with absorbed doses of $500 \mathrm{kGy}$ (Figure 3b) and $1000 \mathrm{kGy}$ (Figure 3c), can be correlated with a red shift and increased line width of the $A_{1 g}$ mode relative to the neighboring uncontaminated regions: 500 kGy, Figure 4b,e and 1000 kGy, Figure 4c,f. The observed changes are qualitatively consistent with n-doping of $\mathrm{MoS}_{2}{ }^{75}$ The magnitude of the observed red shift is smaller than those afforded by the in situ measurements of $1 \mathrm{~L} \mathrm{MoS}_{2}$ field-effect transistors. ${ }^{75}$ However, the adsorption of the carbonaceous aggregates is likely to increase the effective restoring forces acting on $S$ atoms vibrating out-of-plane, thus leading to a reduction in the magnitude of the anticipated $A_{1 \mathrm{~g}}$ redshift.

To gain insights into the effects of radiation-induced $\mathrm{p}$ doping on the optical properties of $1 \mathrm{~L} \mathrm{MoS}_{2}$ crystals, Figure $4 \mathrm{~g}$ shows the PL spectrum of the $1 \mathrm{~L}$ domain prior to and after irradiation with an absorbed dose of $500 \mathrm{kGy}$. A significant increase in the PL intensity and concurrent $\sim 44 \mathrm{meV}$ blue shift of the $\mathrm{A}^{-}$trion are observed upon irradiation. The blue shift of the negative $\mathrm{A}^{-}$trion $\mathrm{PL}$ signal is such that its value increases from $\sim 1.83$ to $\sim 1.87 \mathrm{eV}$, i.e., the $\mathrm{A}^{-}$trion dissociates into the neutral $\mathrm{A}$ exciton at a higher energy. ${ }^{77} \mathrm{We}$ propose that the dissociation of the $\mathrm{A}^{-}$trion could be facilitated by chargetransfer interactions involving occupied conduction band states in $\mathrm{MoS}_{2}$ and $\mathrm{O}_{2}$ molecules adsorbed onto radiation-induced vacancies, akin to the mechanism responsible for the blue shift and line width increase of the $A_{1}^{\prime}$ mode discussed previously. Equivalently, one could state that gamma radiation-induced $\mathrm{p}$ doping of $1 \mathrm{~L} \mathrm{MoS}_{2}$ simply suppresses $\mathrm{A}^{-}$trion formation. Moreover, as trions possess a greater variety of nonradiative decay pathways with respect to excitons, ${ }^{78}$ the significant increase in the PL signal observed (Figure $4 \mathrm{~g}$ ) can also be attributed to the dissociation/suppression of $\mathrm{A}^{-}$trions in gamma-irradiated $1 \mathrm{~L}$ crystals. The optical and out-of-plane vibrational properties of $1 \mathrm{~L}$ crystals irradiated with an absorbed dose of $500 \mathrm{kGy}$ (Figure $4 \mathrm{a}, \mathrm{g}$ ) are consistent with those reported for $1 \mathrm{~L} \mathrm{MoS}_{2}$ in which p-doping is introduced via charge-transfer interactions involving either halogenated solvents $^{79}$ or $\mathrm{O}_{2}$ adsorbed onto heavy ion-irradiated crystals. ${ }^{23}$

Figure $4 \mathrm{~h}$ shows the variation in the PL peak center across the 1 and $2 \mathrm{~L}$ crystals after irradiation with an absorbed dose of $500 \mathrm{kGy}$. It can be observed that the PL emission corresponding to the neutral A exciton at $\sim 1.87 \mathrm{eV}$ is strongly localized within the $1 \mathrm{~L}$ domain that was present prior to irradiation and correlates with the $\sim 1.5 \mathrm{~cm}^{-1}$ blue shift of the $A_{1}^{\prime}$ mode (Figure $4 \mathrm{~b}$ ), unambiguously confirming the radiationinduced p-doping of $1 \mathrm{~L} \mathrm{MoS}_{2}$. However, the peak center of the PL signal originating from within the 1 L-border and $2 \mathrm{~L}$ crystal domains varies by just $\pm 10 \mathrm{meV}$ from the $\sim 1.83 \mathrm{eV}$ value exhibited by $\mathrm{A}^{-}$trion emission, measured prior to irradiation. Moreover, despite the significant blue shift of the PL peak center at the periphery of the 1 L-border after irradiation with an absorbed dose of $1000 \mathrm{kGy}$ (Figure 4i), this shift is not statistically significant within the internal region of the $1 \mathrm{~L}$-border, akin to the $<1 \mathrm{~cm}^{-1}$ blue shift of the $A_{1}^{\prime}$ mode discussed earlier (Figure 4c). Hence, radiation-induced $\mathrm{p}$ doping in $1 \quad \mathrm{~L}^{\mathrm{MoS}} \mathrm{M}_{2}$ domains created by edge-selective radiolytic etching cannot be confirmed definitively.

To assess the influence of crystal morphology on the gamma radiation-induced p-doping of $\mathrm{MoS}_{2}$, a polycrystalline $1 \mathrm{~L}$ film produced by CVD was irradiated with an absorbed dose of 40 $\mathrm{kGy}$, and Raman and PL maps were acquired pre- and postirradiation. Statistical analysis of the maps suggests that the $1 \mathrm{~L}$ film becomes more defective and p-doped upon irradiation; these results are shown in Figure S13, Supporting Information.

\section{CONCLUSIONS}

The effect of high-dose gamma irradiation on the chemical composition, morphology, and vibrational and optical properties of $\mathrm{MoS}_{2}$ crystals under ambient conditions has been systematically evaluated. The deconvolution of XPS spectra as a function of radiation exposure shows that the surface of the $\mathrm{MoS}_{2}$ crystal undergoes significant oxidation via a series of intermediates to ultimately yield $\mathrm{Mo}^{\mathrm{VI}} \mathrm{S}_{y} \mathrm{O}_{x}$ and sulfate species. Oxidation of $\mathrm{MoS}_{2}$ is driven by reactions involving the products of adsorbate radiolysis such as water and adventitious carbon. Moreover, edge-selective radiolytic etching of the uppermost layer of $\mathrm{MoS}_{2}$ crystals is observed after irradiation with an absorbed dose of $500 \mathrm{kGy}$, evidenced by correlative optical microscopy and Raman and PL spectroscopy. The observed etching is facilitated by the higher reactivity of active edge sites and the lower rate of reaction between the products of adsorbate radiolysis and $\mathrm{MoS}_{2}$ layers further from the interface. A blue shift and a line width decrease of the out-ofplane $A_{1}^{\prime}$ vibrational mode are observed upon irradiation of $1 \mathrm{~L}$ $\mathrm{MoS}_{2}$ with an absorbed dose of $500 \mathrm{kGy}$ and are attributed to p-doping. The mechanism of p-doping is expected to involve the adsorption of $\mathrm{O}_{2}$ molecules onto radiation-induced vacancies and subsequent charge-transfer interactions. Consequently, the p-doping of gamma-irradiated $1 \mathrm{~L} \mathrm{MoS}_{2}$ significantly alters the optical properties of the crystal as $\mathrm{A}^{-}$ trions are observed to dissociate into neutral A excitons. In addition to the oxidation, etching, and doping of $\mathrm{MoS}_{2}$ crystals observed at lower doses, upon irradiation with an absorbed dose of $1000 \mathrm{kGy}$, monolayer $\mathrm{MoS}_{2}$ crystals are completely etched from the substrate. Hence, our results provide fundamental insights into key radiation damage mechanisms occurring at the $\mathrm{MoS}_{2}$ crystal surface as well as the threshold of the material's radiation hardness in the $\leq 1000 \mathrm{kGy}$ range. Additionally, we demonstrate that the radiolytic degradation of $\mathrm{MoS}_{2}$ is accelerated in the presence of adsorbed water due to the production of reactive radical species.

We conclude that gamma irradiation of $\mathrm{MoS}_{2}$ results in the adverse changes in the physical and chemical properties, which would lead to a gradual degradation of $\mathrm{MoS}_{2}$-based device performances. For example, vacancies produced by the radiation-induced displacement damage will introduce defect states within the band gap of $\mathrm{MoS}_{2}$. In FETs, such vacancies would act as scattering centers for charge carriers, thus reducing carrier mobility, while radiolytic oxidation would change the chemical composition of $\mathrm{MoS}_{2}$, resulting in deviation from the expected current-voltage characteristics of a pristine $\mathrm{MoS}_{2}$ device. In optoelectronic devices, radiation- 
driven doping would change the intensity of PL, i.e., alter the quantum efficiency of the PL process, and PL emission energy of the device, i.e., alter the wavelength of emission.

We summarize that, owing to their appreciable radiation stability, $2 \mathrm{D} \mathrm{MoS}$-based devices are promising candidates for a variety of demanding nuclear and space applications. However, appropriate consideration must be given to protective shielding and required device operation times as well as to the presence of common adsorbates, such as water, on the surface of $\mathrm{MoS}_{2}$ during radiation exposure.

\section{ASSOCIATED CONTENT}

\section{SI Supporting Information}

The Supporting Information is available free of charge at https://pubs.acs.org/doi/10.1021/acs.jpcc.0c10095.

Compton scattering calculations; X-ray photoelectron spectroscopy of humidity-conditioned $\mathrm{MoS}_{2}$ crystals; Xray photoelectron spectroscopy of polycrystalline monolayer $\mathrm{MoS}_{2}$ films; optical microscopy of $\mathrm{SiO}_{2} / \mathrm{Si}$ substrates; correlative optical microscopy and Raman/ PL mapping of few-layer $\mathrm{MoS}_{2}$ crystals; full Raman spectra of $1 \mathrm{~L} \mathrm{MoS}_{2}$ crystals and $1 \mathrm{~L}$ border region after $500 \mathrm{kGy}$ irradiation; statistical analysis of Raman/PL maps of polycrystalline monolayer $\mathrm{MoS}_{2}$ films (PDF)

\section{AUTHOR INFORMATION}

\section{Corresponding Author}

Aliaksandr Baidak - Department of Chemistry, School of Natural Sciences, University of Manchester, Manchester M13 9PL, United Kingdom; Dalton Cumbrian Facility, Dalton Nuclear Institute, University of Manchester, Cumbria CA24 3HA, United Kingdom; 1 orcid.org/0000-0001-7064-

2082; Email: aliaksandr.baidak@manchester.ac.uk

\section{Authors}

Liam H. Isherwood - Department of Chemistry, School of Natural Sciences, University of Manchester, Manchester M13 9PL, United Kingdom; Dalton Cumbrian Facility, Dalton Nuclear Institute, University of Manchester, Cumbria CA24 3HA, United Kingdom

Gursharanpreet Athwal - Department of Chemistry, School of Natural Sciences, University of Manchester, Manchester M13 9PL, United Kingdom

Ben F. Spencer - Department of Materials, School of Natural Sciences, University of Manchester, Manchester M13 9PL, United Kingdom; (1) orcid.org/0000-0002-1453-5327

Cinzia Casiraghi - Department of Chemistry, School of Natural Sciences, University of Manchester, Manchester M13 9PL, United Kingdom; 0 orcid.org/0000-0001-7185-0377

Complete contact information is available at:

https://pubs.acs.org/10.1021/acs.jpcc.0c10095

\section{Author Contributions}

The manuscript was written through contributions of all authors. All authors have given approval to the final version of the manuscript.

Notes

The authors declare no competing financial interest.

\section{ACKNOWLEDGMENTS}

L.H.I. thanks the Engineering and Physical Sciences Research Council (EPSRC) for financial support provided through the
Doctoral Training Partnership scheme (grant EP/M507969/ 1). A.B. is supported by a research fellowship provided through the Dalton Nuclear Institute, the University of Manchester (Dalton Fellowship), and the EPSRC grant EP/R042179/1. We acknowledge the support of The University of Manchester's Dalton Cumbrian Facility (DCF), a partner in the National Nuclear User Facility, the EPSRC UK National Ion Beam Centre, and the Henry Royce Institute.

\section{REFERENCES}

(1) Elafandi, S.; Christiansen, R.; Azam, N.; Cichon, M.; Park, M.; Hamilton, M. C.; Mahjouri-Samani, M. Monolayer 2D Quantum Materials Subjected to Gamma Irradiation in High-Vacuum for Nuclear and Space Applications. Appl. Phys. Lett. 2020, 116, No. 213105.

(2) Manzeli, S.; Ovchinnikov, D.; Pasquier, D.; Yazyev, O. V.; Kis, A. 2D Transition Metal Dichalcogenides. Nat. Rev. Mater. 2017, 2, No. 17033.

(3) Chhowalla, M.; Shin, H. S.; Eda, G.; Li, L.-J.; Loh, K. P.; Zhang, H. The Chemistry of Two-Dimensional Layered Transition Metal Dichalcogenide Nanosheets. Nat. Chem. 2013, 5, 263-275.

(4) Gusakova, J.; Wang, X.; Shiau, L. L.; Krivosheeva, A.; Shaposhnikov, V.; Borisenko, V.; Gusakov, V.; Tay, B. K. Electronic Properties of Bulk and Monolayer TMDs: Theoretical Study Within DFT Framework (GVJ-2e Method). Phys. Status Solidi A 2017, 214, No. 1700218

(5) Splendiani, A.; Sun, L.; Zhang, Y.; Li, T.; Kim, J.; Chim, C. Y.; Galli, G.; Wang, F. Emerging Photoluminescence in Monolayer $\mathrm{MoS}_{2}$. Nano Lett. 2010, 10, 1271-1275.

(6) Mak, K. F.; Lee, C.; Hone, J.; Shan, J.; Heinz, T. F. Atomically Thin $\mathrm{MoS}_{2}$ : A New Direct-Gap Semiconductor. Phys. Rev. Lett. 2010, 105, No. 136805.

(7) Li, C.; Cao, Q.; Wang, F.; Xiao, Y.; Li, Y.; Delaunay, J. J.; Zhu, H. Engineering Graphene and TMDs Based van Der Waals Heterostructures for Photovoltaic and Photoelectrochemical Solar Energy Conversion. Chem. Soc. Rev. 2018, 47, 4981-5037.

(8) Furchi, M. M.; Höller, F.; Dobusch, L.; Polyushkin, D. K.; Schuler, S.; Mueller, T. Device Physics of van Der Waals Heterojunction Solar Cells. npj 2D Mater. Appl. 2018, 2, 3.

(9) Jariwala, D.; Davoyan, A. R.; Wong, J.; Atwater, H. A. Van Der Waals Materials for Atomically-Thin Photovoltaics: Promise and Outlook. ACS Photonics 2017, 4, 2962-2970.

(10) Xu, J.; Chen, L.; Dai, Y.; Cao, Q.; Sun, Q.; Ding, S.; Zhu, H.; Zhang, D. W. A Two-Dimensional Semiconductor Transistor with Boosted Gate Control and Sensing Ability. Sci. Adv. 2017, 3, No. e1602246.

(11) Shi, L.; Zhao, T. Recent Advances in Inorganic 2D Materials and Their Applications in Lithium and Sodium Batteries. J. Mater. Chem. A 2017, 5, 3735-3758.

(12) Gao, X.; Yang, S.; Feng, Z. Radiation Effects of Space Solar Cells. In High-efficiency solar cells: Physics, materials, and devices; Wang, X.; Wang, Z. M., Eds.; Springer Series in Materials Science; Springer International Publishing: Cham, 2014; 190, 597-622.

(13) Spieler, H. Introduction to Radiation-Resistant Semiconductor Devices and Circuits. AIP Conf. Proc. 1997, 390, 23.

(14) Madauß, L.; Ochedowski, O.; Lebius, H.; Ban-d'Etat, B.; Naylor, C. H.; Johnson, A. T. C.; Kotakoski, J.; Schleberger, M. Defect Engineering of Single- and Few-Layer $\mathrm{MoS}_{2}$ by Swift Heavy Ion Irradiation. 2D Mater. 2017, 4, No. 015034.

(15) Valerius, P.; Kretschmer, S.; Senkovskiy, B. V.; Wu, S.; Hall, J.; Herman, A.; Ehlen, N.; Ghorbani-Asl, M.; Grüneis, A.; Krasheninnikov, A. V.; Michely, T. Reversible Crystalline-toAmorphous Phase Transformation in Monolayer $\mathrm{MoS}_{2}$ under Grazing Ion Irradiation. 2D Mater. 2020, 7, No. 025005.

(16) Thiruraman, J. P.; Fujisawa, K.; Danda, G.; Das, P. M.; Zhang, T.; Bolotsky, A.; Perea-López, N.; Nicolaï, A.; Senet, P.; Terrones, M.; et al. Angstrom-Size Defect Creation and Ionic Transport through Pores in Single-Layer $\mathrm{MoS}_{2}$. Nano Lett. 2018, 18, 1651-1659. 
(17) Liu, X.; Xu, T.; Wu, X.; Zhang, Z.; Yu, J.; Qiu, H.; Hong, J.-H.; Jin, C.-H.; Li, J.-X.; Wang, X.-R.; et al. Top-down Fabrication of SubNanometre Semiconducting Nanoribbons Derived from Molybdenum Disulfide Sheets. Nat. Commun. 2013, 4, 1776.

(18) Arnold, A. J.; Shi, T.; Jovanovic, I.; Das, S. Extraordinary Radiation Hardness of Atomically Thin $\mathrm{MoS}_{2}$. ACS Appl. Mater. Interfaces 2019, 11, 8391-8399.

(19) Ochedowski, O.; Marinov, K.; Wilbs, G.; Keller, G.; Scheuschner, N.; Severin, D.; Bender, M.; Maultzsch, J.; Tegude, F. J.; Schleberger, M. Radiation Hardness of Graphene and $\mathrm{MoS}_{2}$ Field Effect Devices against Swift Heavy Ion Irradiation. J. Appl. Phys. 2013, 113, 214306.

(20) Kim, T.-Y.; Cho, K.; Park, W.; Park, J.; Song, Y.; Hong, S.; Hong, W.-K.; Lee, T. Irradiation Effects of High-Energy Proton Beams on $\mathrm{MoS}_{2}$ Field Effect Transistors. ACS Nano 2014, 8, 27742781.

(21) Parkin, W. M.; Balan, A.; Liang, L.; Das, P. M.; Lamparski, M.; Naylor, C. H.; Rodríguez-Manzo, J. A.; Johnson, A. T. C.; Meunier, V.; Drndić, M. Raman Shifts in Electron-Irradiated Monolayer $\mathrm{MoS}_{2}$. ACS Nano 2016, 10, 4134-4142.

(22) Matsunaga, M.; Higuchi, A.; He, G.; Yamada, T.; Krüger, P.; Ochiai, Y.; Gong, Y.; Vajtai, R.; Ajayan, P. M.; Bird, J. P.; et al. Nanoscale-Barrier Formation Induced by Low-Dose Electron-Beam Exposure in Ultrathin $\mathrm{MoS}_{2}$ Transistors. ACS Nano 2016, 10, 97309737.

(23) He, Z.; Zhao, R.; Chen, X.; Chen, H.; Zhu, Y.; Su, H.; Huang, S.; Xue, J.; Dai, J.; Cheng, S.; et al. Defect Engineering in Single-Layer $\mathrm{MoS}_{2}$ Using Heavy Ion Irradiation. ACS Appl. Mater. Interfaces 2018, 10, 42524-42533.

(24) Tongay, S.; Suh, J.; Ataca, C.; Fan, W.; Luce, A.; Kang, J. S.; Liu, J.; Ko, C.; Raghunathanan, R.; Zhou, J.; et al. Defects Activated Photoluminescence in Two-Dimensional Semiconductors: Interplay between Bound, Charged and Free Excitons. Sci. Rep. 2013, 3, 2657.

(25) Wang, B.; Yang, S.; Chen, J.; Mann, C.; Bushmaker, A.; Cronin, S. B. Radiation-Induced Direct Bandgap Transition in Few-Layer $\mathrm{MoS}_{2}$. Appl. Phys. Lett. 2017, 111, 131101.

(26) Rotunno, E.; Fabbri, F.; Cinquanta, E.; Kaplan, D.; Longo, M.; Lazzarini, L.; Molle, A.; Swaminathan, V.; Salviati, G. Structural, Optical and Compositional Stability of $\mathrm{MoS}_{2}$ Multi-Layer Flakes under High Dose Electron Beam Irradiation. 2D Mater. 2016, 3, No. 025024.

(27) Zhao, G. Y.; Deng, H.; Tyree, N.; Guy, M.; Lisfi, A.; Peng, Q.; Yan, J. A.; Wang, C.; Lan, Y. Recent Progress on Irradiation-Induced Defect Engineering of Two-Dimensional $2 \mathrm{H}-\mathrm{MoS}_{2}$ Few Layers. Appl. Sci. 2019, 9, 678.

(28) Felix, J. F.; da Silva, A. F.; da Silva, S. W.; Qu, F.; Qiu, B.; Ren, J.; de Azevedo, W. M.; Henini, M.; Huang, C.-C. A Comprehensive Study on the Effects of Gamma Radiation on the Physical Properties of a Two-Dimensional $\mathrm{WS}_{2}$ Monolayer Semiconductor. Nanoscale Horizons 2020, 5, 259-267.

(29) Novoselov, K. S.; Jiang, D.; Schedin, F.; Booth, T. J.; Khotkevich, V. V.; Morozov, S. V.; Geim, A. K. Two-Dimensional Atomic Crystals. Proc. Natl. Acad. Sci. 2005, 102, 10451-10453.

(30) Vogl, T.; Sripathy, K.; Sharma, A.; Reddy, P.; Sullivan, J.; Machacek, J. R.; Zhang, L.; Karouta, F.; Buchler, B. C.; Doherty, M. W.; et al. Radiation Tolerance of Two-Dimensional Material-Based Devices for Space Applications. Nat. Commun. 2019, 10, 1202.

(31) Benton, E. R.; Benton, E. V. Space Radiation Dosimetry in Low-Earth Orbit and Beyond. Nucl. Instrum. Methods Phys. Res., Sect. B 2001, 184, 255-294.

(32) Michal, O.; Michal, M.; Izabela, A.; Pawel, K.; Jan, D.; Patrick, P.; Emilie, D. Measurement of the High Gamma Radiation Dose Using The MEMS Based Dosimeter and Radiolisys Effect; 24th MicroMechanics Europe Workshop; Espoo, Finland, 2013, 31-35.

(33) Zhang, Z.; Zhao, Q.; Huang, M.; Zhang, X.; Ouyang, X. Chemisorption of Metallic Radionuclides on a Monolayer $\mathrm{MoS}_{2}$ Nanosheet. Nanoscale Adv. 2019, 1, 114-121.

(34) Zhang, X.-D.; Zhang, J.; Wang, J.; Yang, J.; Chen, J.; Shen, X.; Deng, J.; Deng, D.; Long, W.; Sun, Y.-M.; et al. Highly Catalytic
Nanodots with Renal Clearance for Radiation Protection. ACS Nano 2016, 10, 4511-4519.

(35) Gong, L.; Yan, L.; Zhou, R.; Xie, J.; Wu, W.; Gu, Z. TwoDimensional Transition Metal Dichalcogenide Nanomaterials for Combination Cancer Therapy. J. Mater. Chem. B 2017, 5, 18731895.

(36) Schleberger, M.; Kotakoski, J. 2D Material Science: Defect Engineering by Particle Irradiation. Materials 2018, 11, 1885.

(37) Zhan, Y.; Liu, Z.; Najmaei, S.; Ajayan, P. M.; Lou, J. Large-Area Vapor-Phase Growth and Characterization of $\mathrm{MoS}_{2}$ Atomic Layers on a $\mathrm{SiO}_{2}$ Substrate. Small 2012, 8, 966-971.

(38) Ozden, B.; Khanal, M. P.; Park, J.; Uprety, S.; Mirkhani, V.; Yapabandara, K.; Kim, K.; Kuroda, M.; Bozack, M. J.; Choi, W.; et al. Raman and X-Ray Photoelectron Spectroscopy Investigation of the Effect of Gamma-Ray Irradiation on $\mathrm{MoS}_{2}$. Micro Nano Lett. 2017, 12, $271-274$.

(39) He, Y.; Xiang, X.; Wu, Z.; Li, M.; Deng, H.; Zhang, J.; Yang, G.; Chen, H.; Yuan, Y.; Zu, X. $\gamma$-Ray Dose Dependent Conductivity of $\mathrm{MoS}_{2}$ Nanomaterials at Different Temperatures. CrystEngComm 2019, 21, 6830-6837.

(40) Lee, C.; Yan, H.; Brus, L. E.; Heinz, T. F.; Hone, J.; Ryu, S. Anomalous Lattice Vibrations of Single- and Few-Layer $\mathrm{MoS}_{2}$. ACS Nano 2010, 4, 2695-2700.

(41) Isherwood, L. H.; Hennighausen, Z.; Son, S.-K.; Spencer, B. F.; Wady, P. T.; Shubeita, S. M.; Kar, S.; Casiraghi, C.; Baidak, A. The Influence of Crystal Thickness and Interlayer Interactions on the Properties of Heavy Ion Irradiated $\mathrm{MoS}_{2}$. $2 \mathrm{D}$ Mater. 2020, 7, No. 035011.

(42) Li, K.; Xue, D. Estimation of Electronegativity Values of Elements in Different Valence States. J. Phys. Chem. A 2006, 110, 11332-11337.

(43) Chen, L.; He, X.; Liu, H.; Qian, L.; Kim, S. H. Water Adsorption on Hydrophilic and Hydrophobic Surfaces of Silicon. J. Phys. Chem. C 2018, 122, 11385-11391.

(44) Greczynski, G.; Hultman, L. X-Ray Photoelectron Spectroscopy: Towards Reliable Binding Energy Referencing. Prog. Mater. Sci. 2020, 107, No. 100591.

(45) Barr, T. L.; Seal, S. Nature of the Use of Adventitious Carbon as a Binding Energy Standard. J. Vac. Sci. Technol. A Vacuum, Surfaces, Film. 1995, 13, 1239-1246.

(46) Le Caër, S. Water Radiolysis: Influence of Oxide Surfaces on $\mathrm{H}_{2}$ Production under Ionizing Radiation. Water 2011, 3, 235-253.

(47) Trifunac, A. D.; Werst, D. W.; Percy, L. T. Proton Transfer in Alkane Radical Cations. FDMR Pulse Radiolysis Study. Int. J. Radiat. Appl. Instrum. Part C. Radiat. Phys. Chem. 1989, 34, 547-552.

(48) Avval, T. G.; Cushman, C. V.; Bahr, S.; Dietrich, P.; Meyer, M.; Thißen, A.; Linford, M. R. Dimethyl Sulfoxide by Near-Ambient Pressure XPS. Surf. Sci. Spectra 2019, 26, No. 014020.

(49) Tong, J.; Han, X.; Wang, S.; Jiang, X. Evaluation of Structural Characteristics of Huadian Oil Shale Kerogen Using Direct Techniques (Solid-State ${ }^{13} \mathrm{C}$ NMR, XPS, FT-IR, and XRD). Energy Fuels 2011, 25, 4006-4013.

(50) Castner, D. G.; Hinds, K.; Grainger, D. W. X-Ray Photoelectron Spectroscopy Sulfur 2p Study of Organic Thiol and Disulfide Binding Interactions with Gold Surfaces. Langmuir 1996, 12, 50835086.

(51) Bertolazzi, S.; Bonacchi, S.; Nan, G.; Pershin, A.; Beljonne, D.; Samorì, P. Engineering Chemically Active Defects in Monolayer $\mathrm{MoS}_{2}$ Transistors via Ion-Beam Irradiation and Their Healing via Vapor Deposition of Alkanethiols. Adv. Mater. 2017, 29, No. 1606760.

(52) Wahlqvist, M.; Shchukarev, A. XPS Spectra and Electronic Structure of Group IA Sulfates. J. Electron Spectrosc. Relat. Phenom. 2007, 156-158, 310-314.

(53) Kehrer, J. P.; Robertson, J. D.; Smith, C. V. Free Radicals and Reactive Oxygen Species. In Comprehensive Toxicology; Elsevier, 2010; 277-307.

(54) Buxton, G. V.; Greenstock, C. L.; Helman, W. P.; Ross, A. B. Critical Review of Rate Constants for Reactions of Hydrated 
Electrons, Hydrogen Atoms and Hydroxyl Radicals $(\cdot \mathrm{H} / \cdot \mathrm{OH})$ in Aqueous Solution. J. Phys. Chem. Ref. Data 1988, 17, 513.

(55) Rao, P. S.; Hayon, E. Redox Potentials of Free Radicals. IV. Superoxide and Hydroperoxy Radicals $\cdot \mathrm{O}_{2}{ }^{-}$and $\cdot \mathrm{HO}_{2}$. J. Phys. Chem. 1975, 79, 397-402.

(56) Lefticariu, L.; Pratt, L. A.; LaVerne, J. A.; Schimmelmann, A. Anoxic Pyrite Oxidation by Water Radiolysis Products - A Potential Source of Biosustaining Energy. Earth Planet. Sci. Lett. 2010, 292, 5767.

(57) Lanzalunga, O.; Lapi, A. Recent Photo- and Radiation Chemical Studies of Sulfur Radical Cations. J. Sulfur Chem. 2012, 33, 101-129.

(58) Zeng, N.; Hopkinson, D. G.; Spencer, B. F.; McAdams, S. G.; Tedstone, A. A.; Haigh, S. J.; Lewis, D. J. Direct Synthesis of $\mathrm{MoS}_{2}$ or $\mathrm{MoO}_{3}$ via Thermolysis of a Dialkyl Dithiocarbamato Molybdenum(IV) Complex. Chem. Commun. 2019, 55, 99-102.

(59) Higgins, E. P. C.; McAdams, S. G.; Hopkinson, D. G.; Byrne, C.; Walton, A. S.; Lewis, D. J.; Dryfe, R. A. W. Room-Temperature Production of Nanocrystalline Molybdenum Disulfide $\left(\mathrm{MoS}_{2}\right)$ at the Liquid-Liquid Interface. Chem. Mater. 2019, 31, 5384-5391.

(60) Il'in, E. G.; Beirakhov, A. G.; Teterin, Y. A.; Maslakov, K. I.; Teterin, A. Y. Surface Morphology and Composition of Nanocrystalline $\mathrm{MoO}_{2}$ Produced via the Thermal Decomposition of the $\mathrm{MoO}_{2}(\mathrm{i}-$ $\left.\mathrm{C}_{3} \mathrm{H}_{7} \mathrm{NHO}\right)_{2}$ Complex. Inorg. Mater. 2017, 53, 602-612.

(61) Zhao, B.; Shang, C.; Qi, N.; Chen, Z. Y.; Chen, Z. Q. Stability of Defects in Monolayer $\mathrm{MoS}_{2}$ and Their Interaction with $\mathrm{O}_{2}$ Molecule: A First-Principles Study. Appl. Surf. Sci. 2017, 412, 385393.

(62) Willis, C.; Boyd, A. W.; Young, M. J.; Armstrong, D. A. Radiation Chemistry of Gaseous Oxygen: Experimental and Calculated Yields. Can. J. Chem. 1970, 48, 1505-1514.

(63) Shakya, J.; Kumar, S.; Mohanty, T. Role of Oxygen Adsorption in Modification of Optical and Surface Electronic Properties of $\mathrm{MoS}_{2}$. J. Appl. Phys. 2018, 123, 165103.

(64) Benoist, L.; Gonbeau, D.; Pfister-Guillouzo, G.; Schmidt, E.; Meunier, G.; Levasseur, A. X-Ray Photoelectron Spectroscopy Characterization of Amorphous Molybdenum Oxysulfide Thin Films. Thin Solid Films 1995, 258, 110-114.

(65) Fan, X.; Fang, G.; Qin, P.; Sun, N.; Liu, N.; Zheng, Q.; Cheng, F.; Yuan, L.; Zhao, X. Deposition Temperature Effect of RF Magnetron Sputtered Molybdenum Oxide Films on the Power Conversion Efficiency of Bulk-Heterojunction Solar Cells. J. Phys. D: Appl. Phys. 2011, 44, No. 045101.

(66) Qin, P.; Fang, G.; Ke, W.; Cheng, F.; Zheng, Q.; Wan, J.; Lei, H.; Zhao, X. In Situ Growth of Double-Layer $\mathrm{MoO}_{3} / \mathrm{MoS}_{2}$ Film from $\mathrm{MoS}_{2}$ for Hole-Transport Layers in Organic Solar Cell. J. Mater. Chem. A 2014, 2, 2742.

(67) Jaramillo, T. F.; Jorgensen, K. P.; Bonde, J.; Nielsen, J. H.; Horch, S.; Chorkendorff, I. Identification of Active Edge Sites for Electrochemical $\mathrm{H}_{2}$ Evolution from $\mathrm{MoS}_{2}$ Nanocatalysts. Science 2007, 317, 100-102.

(68) Xie, J.; Zhang, H.; Li, S.; Wang, R.; Sun, X.; Zhou, M.; Zhou, J.; Lou, X. W. D.; Xie, Y. Defect-Rich $\mathrm{MoS}_{2}$ Ultrathin Nanosheets with Additional Active Edge Sites for Enhanced Electrocatalytic Hydrogen Evolution. Adv. Mater. 2013, 25, 5807-5813.

(69) Ottaviano, L.; Palleschi, S.; Perrozzi, F.; D’Olimpio, G.; Priante, F.; Donarelli, M.; Benassi, P.; Nardone, M.; Gonchigsuren, M.; Gombosuren, M.; Lucia, A.; Moccia, G.; Cacioppo, O. A. Mechanical Exfoliation and Layer Number Identification of $\mathrm{MoS}_{2}$ Revisited. $2 \mathrm{D}$ Mater. 2017, 4, No. 045013.

(70) Komsa, H. P.; Krasheninnikov, A. V. Native Defects in Bulk and Monolayer $\mathrm{MoS}_{2}$ from First Principles. Phys. Rev. B 2015, 91, No. 125304.

(71) Molina-Sánchez, A.; Hummer, K.; Wirtz, L. Vibrational and Optical Properties of $\mathrm{MoS}_{2}$ : From Monolayer to Bulk. Surf. Sci. Rep. 2015, 70, 554-586.

(72) Luo, X.; Zhao, Y.; Zhang, J.; Xiong, Q.; Quek, S. Y. Anomalous Frequency Trends in $\mathrm{MoS}_{2}$ Thin Films Attributed to Surface Effects. Phys. Rev. B 2013, 88, No. 075320.
(73) Scheuschner, N.; Ochedowski, O.; Kaulitz, A.-M.; Gillen, R.; Schleberger, M.; Maultzsch, J. Photoluminescence of Freestanding Single- and Few-Layer $\mathrm{MoS}_{2}$. Phys. Rev. B 2014, 89, No. 125406.

(74) Ye, M.; Winslow, D.; Zhang, D.; Pandey, R.; Yap, Y. Recent Advancement on the Optical Properties of Two-Dimensional Molybdenum Disulfide $\left(\mathrm{MoS}_{2}\right)$ Thin Films. Photonics 2015, 2, $288-307$.

(75) Chakraborty, B.; Bera, A.; Muthu, D. V. S.; Bhowmick, S.; Waghmare, U. V.; Sood, A. K. Symmetry-Dependent Phonon Renormalization in Monolayer $\mathrm{MoS}_{2}$ Transistor. Phys. Rev. B 2012, 85, No. 161403.

(76) Nan, H.; Wang, Z.; Wang, W.; Liang, Z.; Lu, Y.; Chen, Q.; He, D.; Tan, P.; Miao, F.; Wang, X.; Wang, J.; Ni, Z. Strong Photoluminescence Enhancement of $\mathrm{MoS}_{2}$ through Defect Engineering and Oxygen Bonding. ACS Nano 2014, 8, 5738-5745.

(77) Mak, K. F.; He, K.; Lee, C.; Lee, G. H.; Hone, J.; Heinz, T. F.; Shan, J. Tightly Bound Trions in Monolayer $\mathrm{MoS}_{2}$. Nat. Mater. 2013, 12, 207-211.

(78) Jha, P. P.; Guyot-Sionnest, P. Trion Decay in Colloidal Quantum Dots. ACS Nano 2009, 3, 1011-1015.

(79) Mao, N.; Chen, Y.; Liu, D.; Zhang, J.; Xie, L. Solvatochromic Effect on the Photoluminescence of $\mathrm{MoS}_{2}$ Monolayers. Small 2013, 9, 1312-1315. 